\title{
La chapelle des donateurs a Soğanlı, nouvelle fondation de la famille des Sképidès
}

\section{Anaïs Lamesa}

\section{(2) OpenEdition}

1 Journals

Édition électronique

URL : http://journals.openedition.org/anatoliaantiqua/354

DOI : 10.4000/anatoliaantiqua.354

\section{Éditeur}

IFEA

Édition imprimée

Date de publication : 1 juin 2015

Pagination : 179-198

ISBN : 9782362450600

ISSN : 1018-1946

\section{Référence électronique}

Anaïs Lamesa, "La chapelle des donateurs a Soğanlı, nouvelle fondation de la famille des Sképidès »,

Anatolia Antiqua [En ligne], XXIII | 2015, mis en ligne le 30 juin 2018, consulté le 18 décembre 2020.

URL : http://journals.openedition.org/anatoliaantiqua/354 ; DOI : https://doi.org/10.4000/

anatoliaantiqua.354 


\title{
ANATOLIA ANTIQUA ESKI ANADOLU
}

\author{
XXIII
}

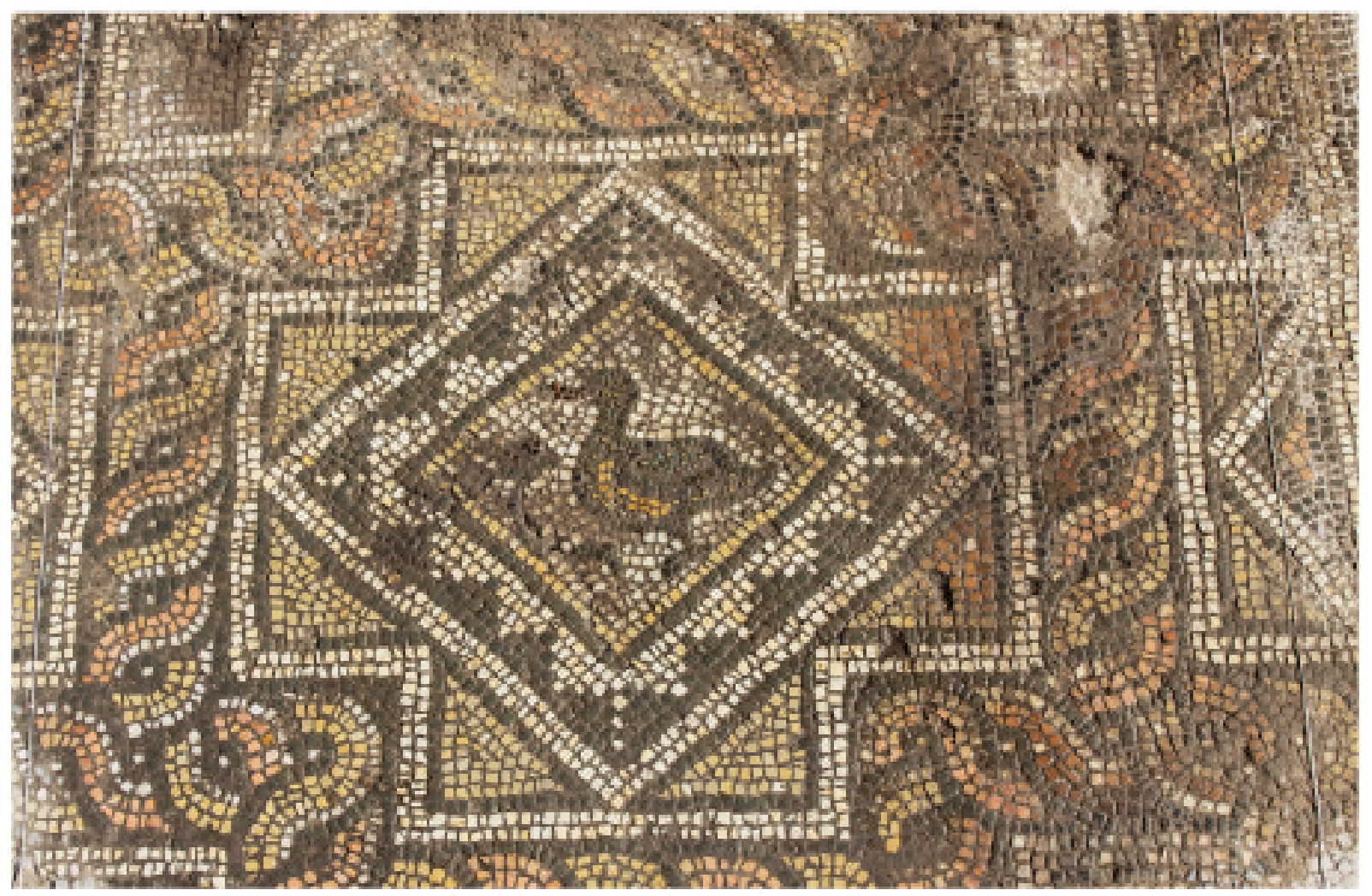

INSTITUT FRANC̣AIS D'ETUDES ANATOLIENNES GEORGES-DUMEZIL CNRS USR 3131 


\section{TABLE DES MATIERES}

Hélène BOUILLON,

On the anatolian origins of some Late Bronze egyptian vessel forms

Agneta FRECCERO,

Marble trade in Antiquity. Looking at Labraunda

Şehnaz ERASLAN,

Dionysus and Ariadne in the light of Antiocheia and Zeugma Mosaics

Ergün LAFLI et Gülseren KAN ŞAHIN,

Middle Byzantine ceramics from Southwestern Paphlagonia

Mustafa AKASLAN, Doğan DEMIRCİ et Özgür PERÇİN en collaboration avec Guy LABARRE, L'église paléochrétienne de Bindeos (Pisidie)

Anaïs LAMESA,

La chapelle des Donateurs à Soğanlı, nouvelle fondation de la famille des Sképidès

Martine ASSENAT et Antoine PEREZ,

Localisation et chronologie des moulins hydrauliques d'Amida. A propos d'Ammien Marcellin,

XVIII, 8,11

Helke KAMMERER-GROTHAUS,

$»$ Ubi Troia fuit«

Atzik-Köy - Eine Theorie von Heinrich Nikolaus Ulrichs (1843)

CHRONIQUES DES TRAVAUX ARCHEOLOGIQUES EN TURQUIE, 2015

Sami PATACI et Ergün LAFLI,

Surveys in Ardahan on the turkish-georgian borderline in 2013 and 2014

Çĭ̆dem MANER,

Preliminary report on the second season of the Konya-Ereğli survey (KEYAR) 2014

Dominique BEYER, Can KARAVUL, Françoise LAROCHE-TRAUNECKER et Aksel TiBBET,

Rapport préliminaire sur les travaux de la mission archéologique de Zeyve Höyük-Porsuk 2014

Jean-Charles MORETTI avec la collaboration de Nicolas BRESCH, Isabel BONORA,

Jean-Jacques MALMARY et Olivier RISS,

Claros, le temple d'Apollon : travaux réalisés en 2014

Olivier HENRY et Erika ANDERSSON, Christophe BOST, Ömür Dünya ÇAKMAKLI, Angela COMMITO, Mélissa CORMIER-HUGUET, Peter DE STAEBLER, Pierre DUPONT, Duygu ERGENÇ, Axel FREJMAN, Banu KEPENEK, Pascal LEBOUTEILLER, Haral NILSSON, Felipe ROJAS, Baptiste VERGNAUD, 


\section{LA CHAPELLE DES DONATEURS A SOĞANLI, NOUVELLE FONDATION DE LA FAMILLE DES SKEPIDES}

\section{PRESENTATION GENERALE DE L'EGLISE}

Situé au cœur de la Cappadoce touristique dans la préfecture de Kayseri, le site de Soğanll est bien connu des chercheurs. Mentionné par G. de Jerphanion dans son ouvrage sur les églises rupestres de Cappadoce, les monuments du site ont été publiés à diverses reprises ${ }^{1}$.

Le musée s'étend sur deux vallées. La chapelle des Donateurs se situe dans le bras nord, rive gauche dans un cône avant les églises de Karabaş et de Canavar ${ }^{2}$. Elle a été découverte lors de prospections autorisées par le musée de Kayseri en $2010^{3}$. La porte de l'église était fermée par un mur de parpaing qui, grâce à l'intervention du maire, a pu être ouverte ; seuls de discrets restes de panneaux peints étaient visibles de la route.

L'église est excavée dans une cheminée de fée où plusieurs arcosolia sont également creusés. On y accède par une rampe pentue. Plusieurs salles sont creusées à proximité et utilisées actuellement comme dépôts et bergerie. Depuis sa découverte, l'église est devenue un dépôt de paille ce qui a engendré une détérioration importante des peintures.
Une porte s'ouvre à l'Ouest et paraît être la porte d'origine de l'église. Elle donne accès à une nef de forme oblongue, couverte d'une voûte en berceau (Fig. 1). La nef est terminée par une abside dont une grande partie a déversée dans la vallée ; il ne reste qu'une partie du siège sud. Au Nord-Est, une ouverture est pratiquée dans le mur nord, elle donne sur une salle couverte d'un plafond plat en partie détruite.

Les parois de la nef et la voûte sont peintes ; la partie du siège sud de l'abside semble également enduite comme la salle adjacente où des restes d'un épais enduit blanc sont visibles. L'ensemble du complexe semblait entièrement peint.

L'intérêt de ce monument réside dans son iconographie originale et dans son contexte historique puisqu'elle permet de mettre en lumière l'activité de la famille des Sképidès, élites de l'aristocratie militaire locale ${ }^{4}$. Elle sera également l'occasion de questionner la situation de Soğanlı dans les provinces impériales de l'Empire byzantin du $11^{\mathrm{e}}$ siècle.

Nous débuterons par l'étude du décor, pour aborder par la suite sa datation et son contexte historique et politique.

*) Doctorante en histoire antique sous la direction de G. Traina à Paris-Sorbonne. Chercheuse associée à l'Institut français d'étude Anatolienne (IFEA) USR 3131 et au laboratoire TP2C de Lattès UMR 5140.

1) Un premier article sur l'église, qui ne traite ni des inscriptions, ni de la fonction ou de la localisation de l'église, a été publié à la suite d'une conférence lors des journées cappadociennes réalisées le 2 février 2014 dans le Bulletin des Amis de la Cappadoce d'avril 2014. Je remercie N. Thierry pour ses conseils.

Les ouvrages de référence pour le site de Soğanlı sont Jerphanion 1942 : II 249-382 et plus spécifiquement pour les églises de Karabaş et Canavar : II 333-368 ; Restle 1967 : 41-64 et plus spécifiquement sur les églises de Karabaş et Canavar : 46-49 et 162-166; Hild et Restle 1981 : 283 ; Rodley 1985 : 193-202 pour Karabaş Kilise ; Jolivet-Lévy 1991 : 255-272 et plus spécifiquement 266-272 ; Thierry 2002 : fiche 4 et pour les églises de Karabaş et Canavar : 187-190, 202-203 et fiche 47. La liste des représentations de donateurs militaires a été établie par Jolivet-Lévy 2012: 157

2) Le nom de l'église a été proposé par Pierre Lucas lors de sa visite de l'église. Je le remercie pour son aide durant mes pérégrinations cappadociennes. L'appellation de 'chapelle des Donateurs' est employée à défaut dans la mesure où la dédicace de l'église n'est pas connue. Sur l'emploi du terme donateur, personnage représenté en prière les mains vides voir : Jolivet-Lévy 2002 : 359 note 10. Les coordonnées GPS de l'église sont (en degré décimaux) Lat. 38.347418 et Long. 34.970686.

3) Je souhaite remercier chaleureusement le ministère des affaires culturelles et du tourisme turc pour m'avoir autorisé à prospecter dans la province $\left(n^{\circ} 07375590\right)$ ainsi que les membres de l'IFEA pour les soutiens logistiques apportés durant ces recherches effectuées en Turquie et leurs présences tout au long de mon travail de doctorat, ainsi qu'Aksel Tibet pour sa relecture attentive.

4) Jolivet-Lévy 2012 : 151-155 réalise un bilan sur les fondations religieuses de Soğanlı ayant vraisemblablement bénéficiées de donations de militaires. 


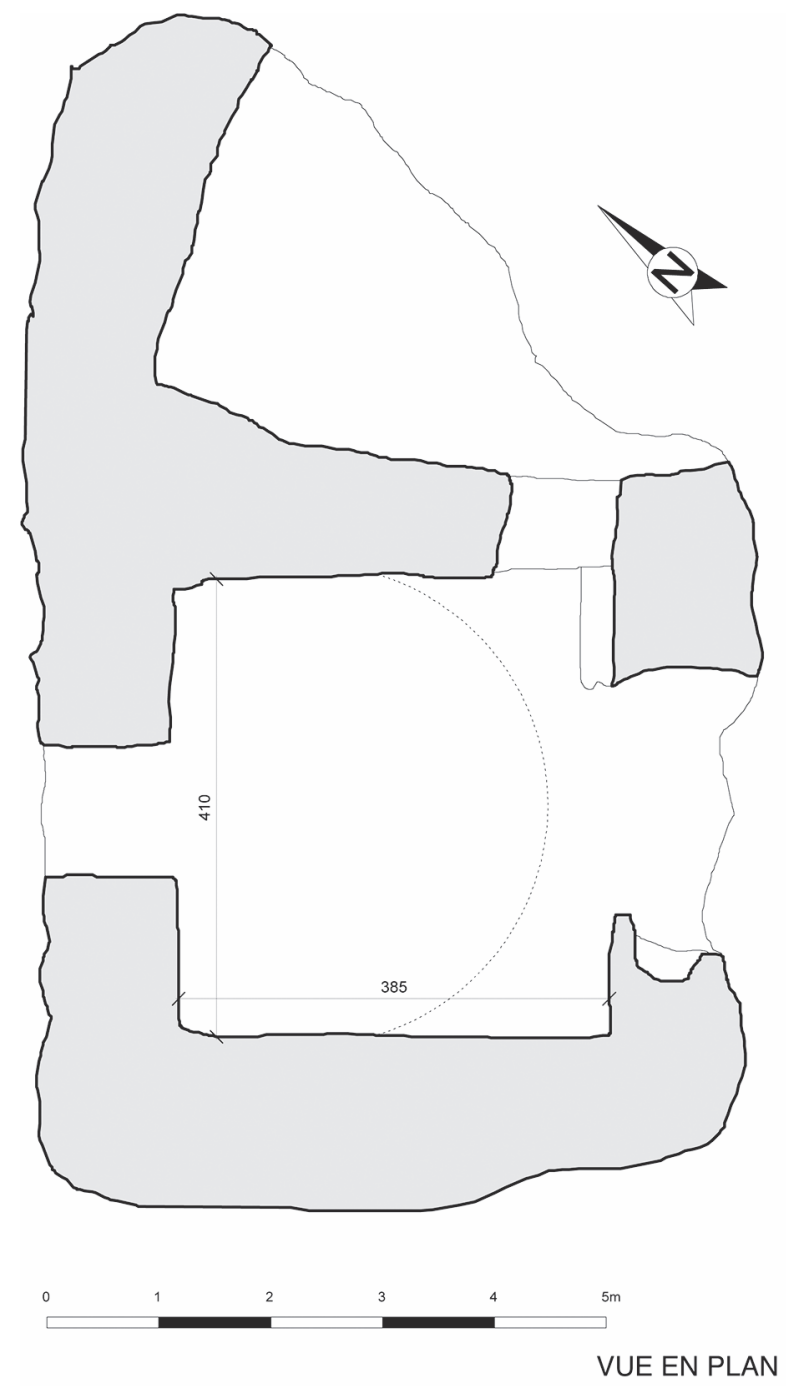

Fig. 1 : Plan de la chapelle des Donateurs (A. Lamesa et V. Dubois).

\section{DESCRIPTION DE LA VOUTE}

Le premier panneau est de grande dimension, il se situe au Sud-Est de la voûte à proximité de l'arc triomphal (Fig. 2). La scène, délimitée par un liserai ocre, est très abîmée ; elle n'a pas conservé ses couleurs d'origine et seule l'esquisse rouge est conservée.

Au centre de la composition, un personnage féminin allongé sur un élément ovale qui ressemble à une couche, est couvert d'un voile.

Différentes têtes sont visibles de part et d'autre $\mathrm{du}$ personnage, en haut de la composition ; elles émergent de deux traits épais rouges légèrement courbés.
Au bas du panneau, plusieurs éléments forment un bandeau. Un homme, à gauche, est assis et tourne le dos au personnage féminin. La scène la plus au centre semble constituer de deux personnages qui entourent un troisième de plus petite taille. A droite, on distingue deux têtes, dont l'une est cornue, situées dans le prolongement d'un des traits épais rouge.

Il est aisé de reconnaître dans ce premier panneau la Nativité, qui reprend l'ensemble des éléments iconographiques traditionnels de la scène. La Vierge, couchée au centre, est entourée d'anges et de bergers. A sa droite, Joseph lui tourne le dos, pensif. Le bain de l'enfant ainsi que l'âne et le bœuf complètent le bandeau bas de la scène.

Le deuxième panneau est de plus petite dimension, la scène est également délimitée par un liserai rouge (Fig. 3). Tout le haut de la composition est perdu, mais la partie basse a conservé ses couleurs pastelles.

Deux personnages dont on discerne le bas de la toge sont situés de part et d'autre d'un élément central. Deux pieds de cet objet sont visibles ; ils sont de couleur marron et se distinguent l'un de l'autre grâce à un liserai de couleur plus clair qui marque une séparation entre les deux. Ils reposent sur le sol qui, a cet endroit, forme un triangle blanc. Le fond de la composition est bicolore : vert en haut et noir en bas.

Le personnage à la gauche de cet élément porte une robe blanche et un châle frangé mauve. Du personnage de droite, un bras, des cheveux blancs, un nimbe et une partie de sa toge rose sont visibles ; un voile à motifs cordiformes couvre son bras qu'il avance, au-dessus de l'élément central, vers le premier personnage.

Cette scène n'est pas aisée à identifier. Il pourrait s'agir de la Présentation au Temple. La Vierge couverte de son maphorium - de même couleur et de même type que celui qu'elle porte dans la scène de dévotion sur la partie orientale de la paroi sud tend l'enfant Jésus à Siméon, dont les mains sont couvertes d'un linge, prêt à recevoir l'enfant audessus de l'autel au centre de la composition.

Une inscription située à proximité de Siméon confirme notre identification (Fig. 4). Au-dessus de la scène sont peintes de manière horizontale les lettres $o v o \theta$ et verticalement les lettres $\varepsilon o \delta o . o$. Il s'agit du nom du personnage [ $\Sigma \mu \varepsilon]$ óv ó $\Theta \varepsilon o \delta o ́[\chi] o[\varsigma]$ / Siméon le Théodochos. Cette désignation de Siméon, étrange selon G. de Jerphanion, est également employée dans la scène de la présentation au Temple de Karabaş Kilise 5 . 


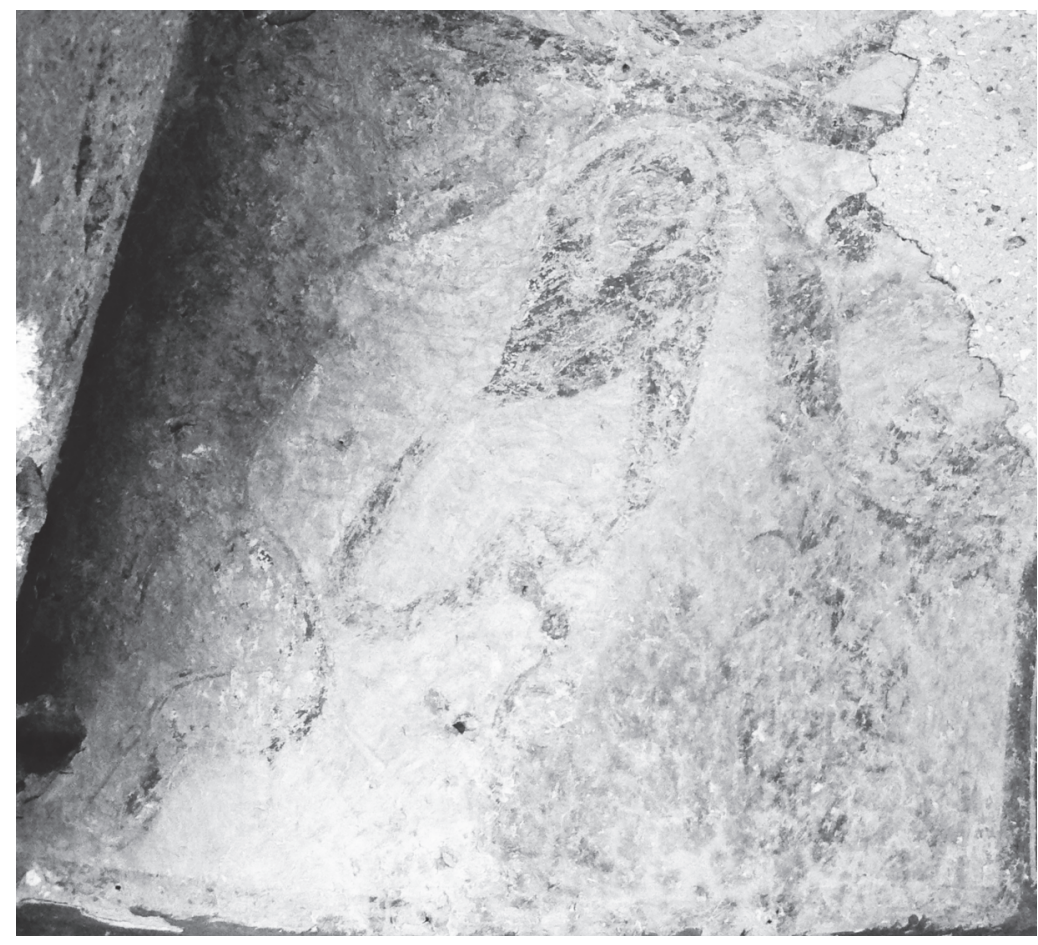

Fig. 2 : Nativité, partie sud-est de la voûte de la nef.

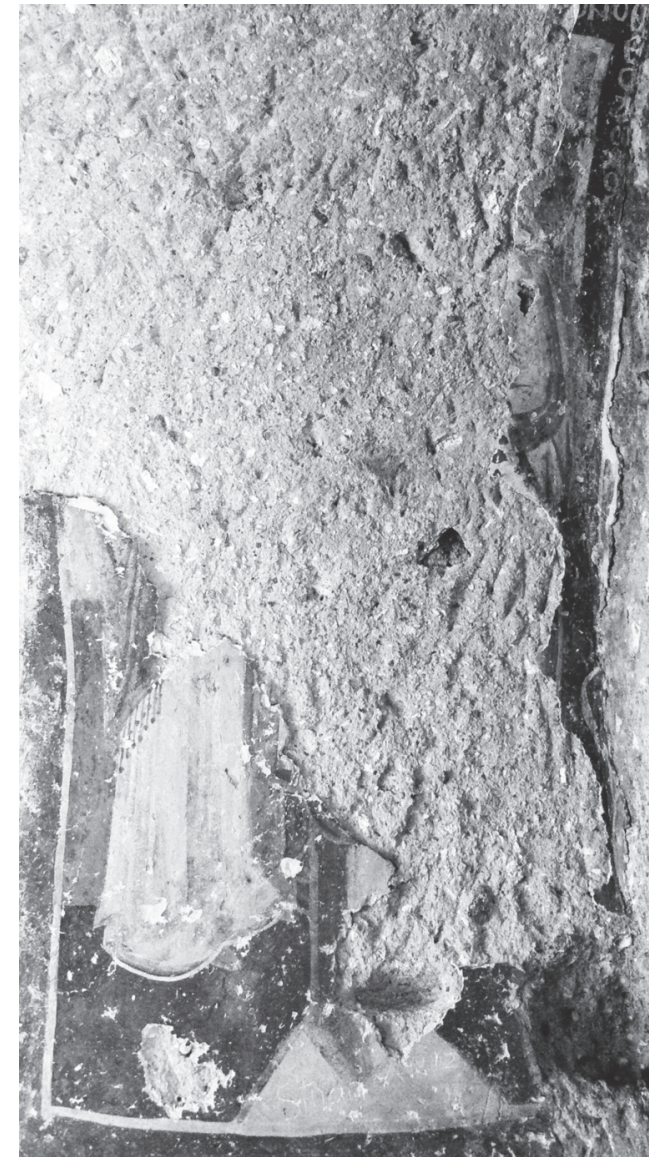

Fig. 3 : Présentation au Temple, partie sud-ouest de la voûte de la nef.

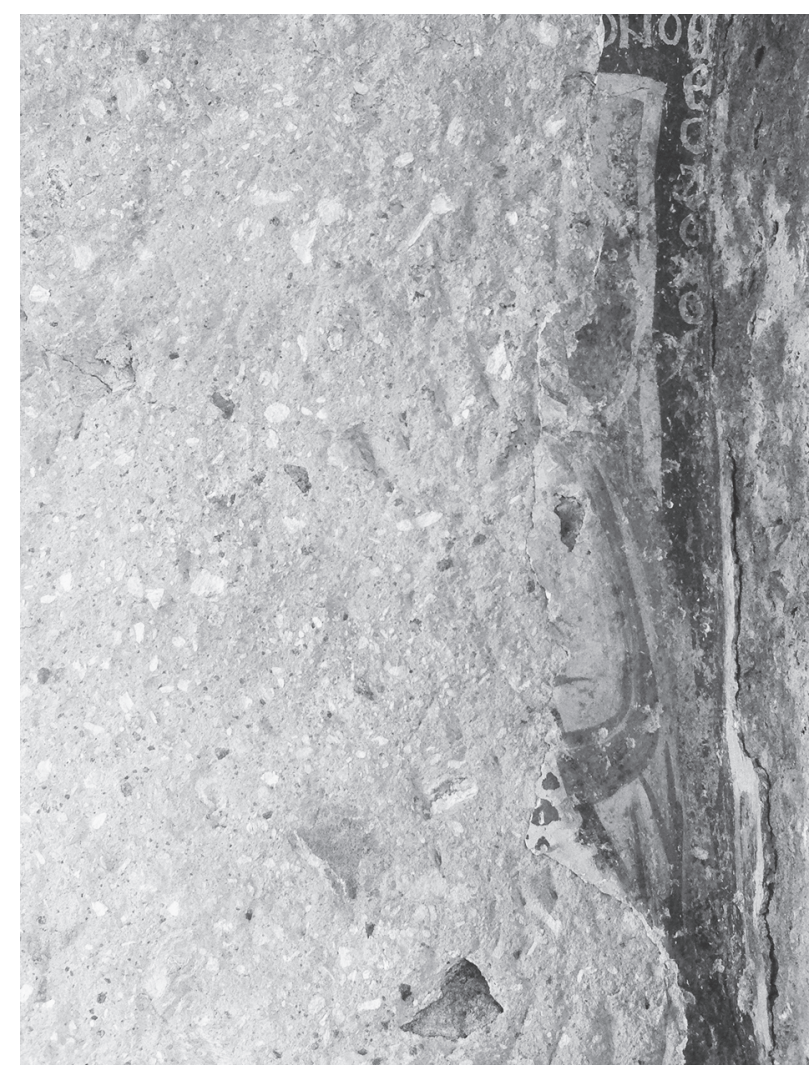

Fig. 4 : Détail de Siméon et inscription le désignant. 


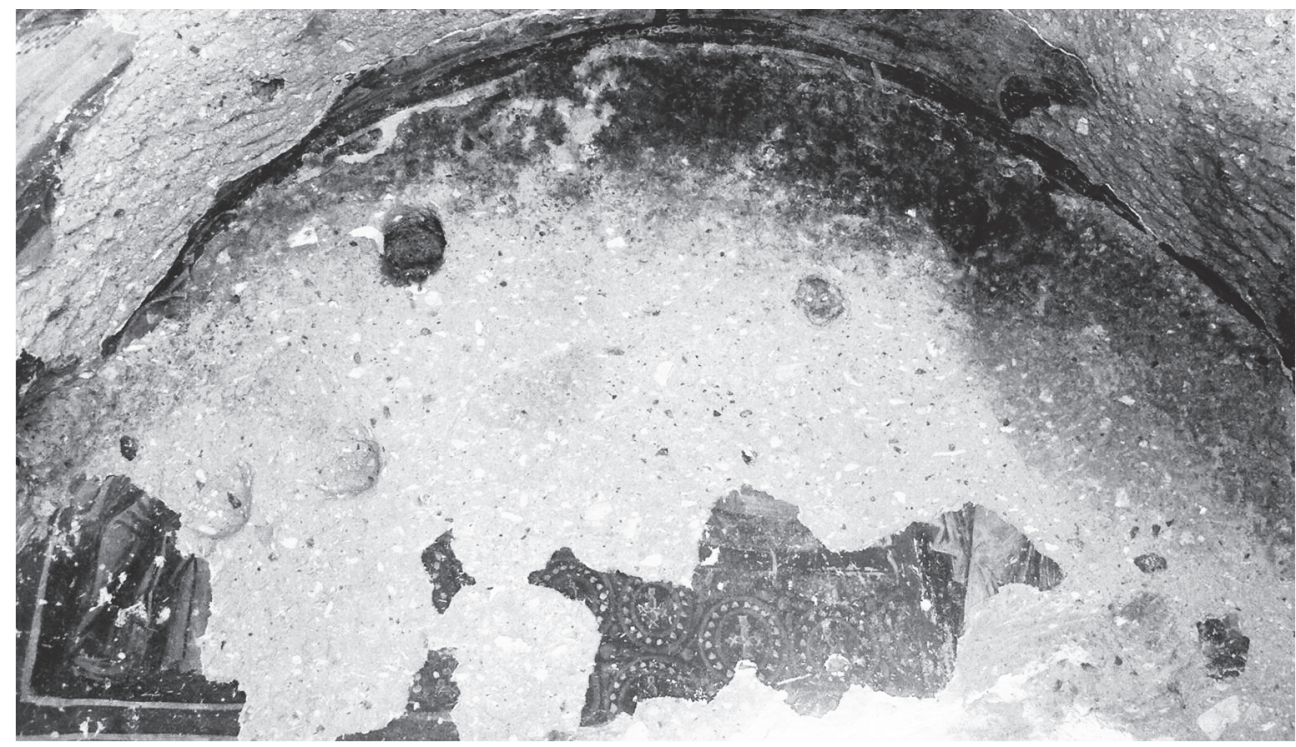

Fig. 5 : Dormition, lunule située sur la paroi ouest de la nef.

La représentation de cette scène est souvent plus développée en Cappadoce. Deux personnages (Joseph et Anne) sont placés derrière Marie et Siméon. Cependant, G. de Jerphanion remarque que sa composition varie d'une église à l'autre. Une iconographie restreinte aux seuls trois personnages principaux se trouve peinte à la chapelle Saint-Eustathe de Göreme ${ }^{6}$. A El-Nazar de Göreme, le changement de composition est motivé par la place disponible ${ }^{7}$. Enfin ce type iconographique s'observe dans la chapelle $\mathrm{n}^{\circ} 1$ de Güllü Dere ou à Gök Kilise ${ }^{8}$. Cette variété s'expliquerait principalement par les choix suivis par le peintre qui, dans notre église, a souhaité consacrer davantage de place à la Nativité.

Enfin, un dernier argument en faveur de l'identification de la scène à la Présentation au Temple est son association à la Nativité qui, en Cappadoce, est courante. A Karabaş Kilise, elle suit la Nativité et se situe au Sud-Ouest de la voûte à proximité de l'entrée, comme dans notre église.

Le troisième panneau est peint dans la lunule au-dessus de la porte d'entrée (Fig. 5). La scène est très abîmée : on observe au premier plan un élément de couleur marron évoquant un cadre rectangulaire en bois où est suspendu un tissu à l'aide de tringles rondes. Le tissu est décoré de motifs de croix inscrites dans des cercles gemmés.
Deux personnages, dont l'un est nimbé, se tiennent debout à droite de l'élément. Ils portent chacun une toge de couleur pastelle. A gauche du meuble en bois, on distingue un autre personnage, de grande taille, habillé d'une toge. Dans le ciel, un fragment d'ailes de couleur blanche et rouge est encore visible.

L'iconographie de cette scène - un meuble central entouré de personnages qui pourraient être des apôtres puisqu'ils portent des toges, et la présence d'un ange dans le coin supérieur droit de la composition - pourrait permettre de l'identifier à la Dormition. Sa localisation sur la paroi ouest au-dessus de la porte d'entrée du naos est plutôt rare en Cappadoce bien que traditionnelle dans le monde byzantin ${ }^{9}$. Il semble que seulement trois églises soient décorées d'une Dormition située sur la paroi ouest $\mathrm{du}$ naos, au-dessus de la porte : Göreme $\mathrm{n}^{\circ} 2 \mathrm{~d}$, Yüsekli ${ }^{\circ} 1$ et Kale Kilise à Selime ${ }^{10}$.

Le quatrième panneau, de grande dimension, qui se situe au Nord-Ouest de la voûte de la chapelle, est très abîmé (Fig. 6). A son extrémité ouest, un nimbe et des mains tendues sont peints au-dessous d'un bras et d'une main accrochés à un élément rectangulaire. Un cercle blanc est situé au-dessus du bras du supplicié. Au centre du panneau, une ligne rouge est peinte à proximité d'une inscription et d'un fragment de vêtement stylisant une armure. 


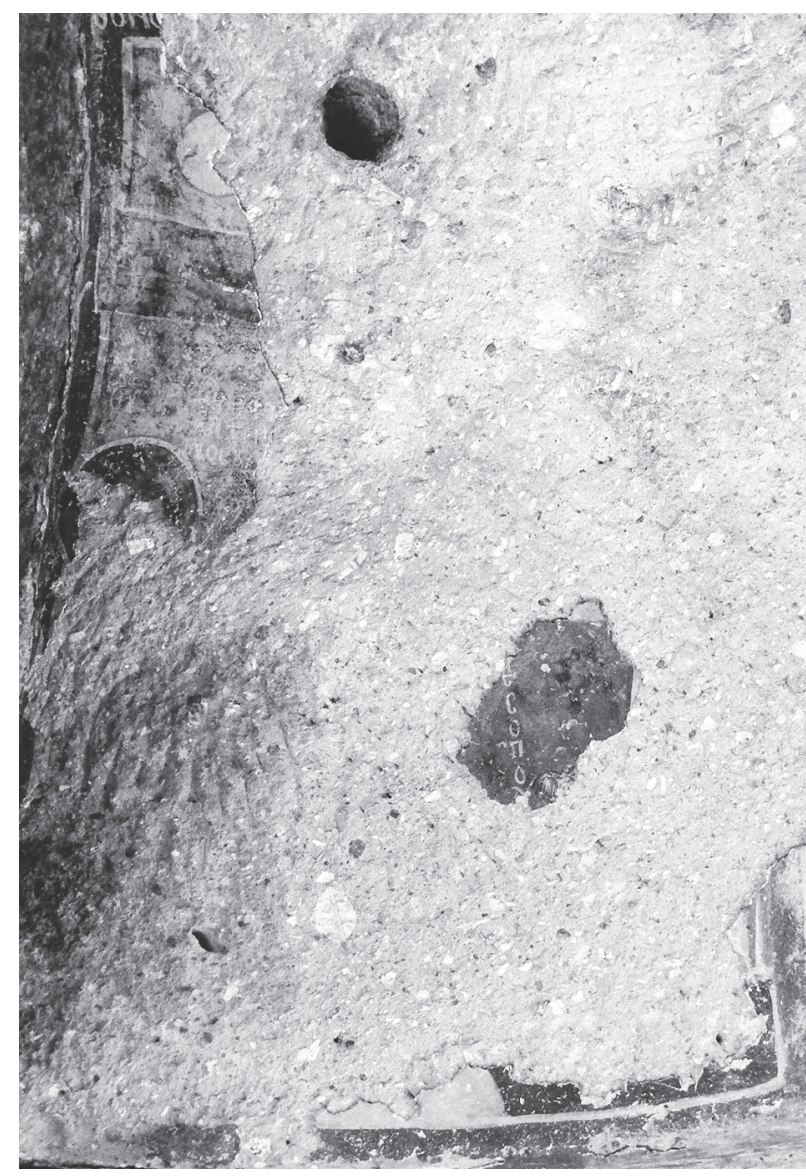

Fig. 6 : Crucifixion, partie nord-ouest de la voûte de la nef.

Cette scène grâce au bras clouté sur un fragment de bois peut être identifiée à une Crucifixion. Le Christ martyrisé est représenté entre sa mère à gauche et l'un des deux soldats nommés 'Eøo $\pi(0$ ộ), le porte-éponge à droite. L'astre solaire, conformément à la tradition cappadocienne est représenté dans le coin gauche du panneau ${ }^{11}$. Il est possible que Saint Jean-Baptiste ait été également représenté à droite du Christ mais il n'en reste aucune trace.

L'inscription à proximité de la Vierge est très abîmée. Elle se répartit sur trois lignes :

$$
\begin{aligned}
& \Theta(\varepsilon o) \tilde{v}--- \\
& \text { [ó] Io[s] } \sigma(o \tilde{)})^{12} \text {. }
\end{aligned}
$$

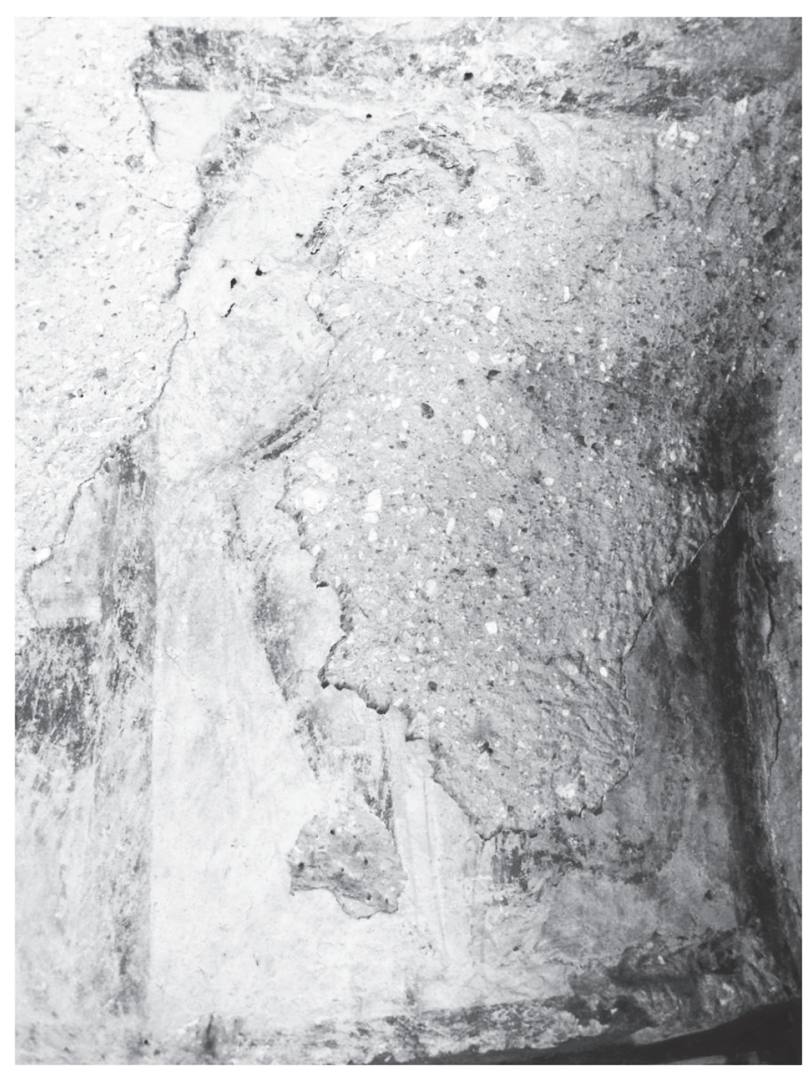

Fig. 7 : Annonciation?, partie nord-est de la voûte de la nef.

Une croix termine l'inscription. Elle rappelle les paroles du Christ qui, sur la croix, désigne sa mère à Jean-Baptiste. Ce texte est un argument supplémentaire permettant de penser que le Prodrome était peint dans la composition.

Le cinquième et dernier panneau de la voûte se situe à l'extrémité nord-est (Fig. 7). Il est en très mauvais état de conservation; la couche de peinture est tombée découvrant l'esquisse rouge.

On observe un personnage de grande taille qui semble couvert d'un châle, situé à la gauche d'un élément arqué. A droite du panneau, une forme triangulaire est peinte.

L'identification de la scène est très difficile. Il pourrait s'agir de l'Annonciation, scène trouvant en Cappadoce une place privilégié à proximité de l'abside dans la partie nord de la voûte ou de la paroi ${ }^{13}$.

11) Jerphanion $1925:$ I 89.

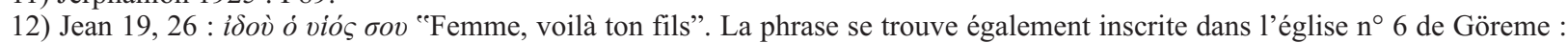
Jerphanion 1925 : I 102 note 1. Le premier monogramme identifie la Vierge : [Mít $\eta \rho] \Theta(\varepsilon \circ) \tilde{v}$.

13) Pour exemple : Saint-Jean-Baptiste à Çavuşin, église $n^{\circ} 1$ de Güllü Dere, Yusuf Koç Kilisesi, Babayan à İbrahimpaşa ; Eski Gümüş dans la région de Niğde, Çömlekçi Kilisesi à Güzelyurt, Yılanlı Kilise et Açıkel Ağa Kilisesi dans la région du Hasan Dağ : Jolivet-Lévy $1991: 26,27,72,165,278,293,308$ et 327. 


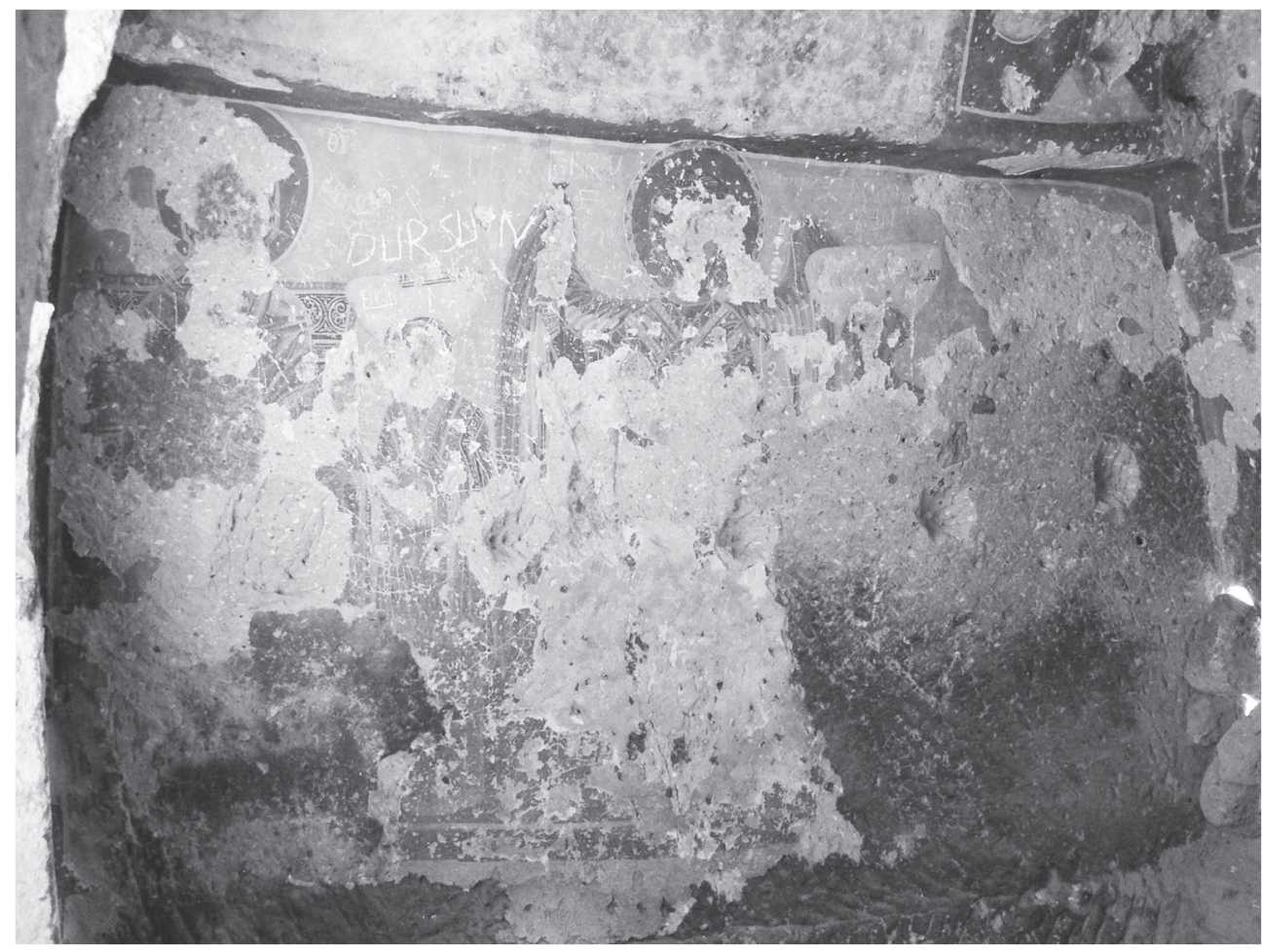

Fig. 8 : Scène de dévotion, paroi sud de la nef.

\section{DESCRIPTION DES PAROIS DE LA NEF ET DE L'ARC TRIOMPHA}

La scène de dévotion se développe sur la paroi sud et une partie de la paroi ouest de l'église (Fig. 8). De très vaste dimension, elle est - à notre connaissance - la plus importante scène représentant des laïcs en Cappadoce, tant du point de vue du nombre de laïcs représentés que la surface attribuée au sujet. Elle est composée de cinq 'donateurs' et de deux figures Néotestamentaires : la Vierge et un Archange.

Située complètement à l'Est du panneau à proximité immédiate de l'abside, on trouve une Vierge trônant. Elle est couverte de son maphorion, de couleur mauve et d'une toge ${ }^{14}$. Son visage est malheureusement abîmé. Le siège où elle est assise est décoré de volutes et de gemmes, il imite le bois. Elle tient l'enfant Jésus sur son giron que l'on distingue grâce au reste du nimbe crucigère.

Un premier personnage figure à son côté. Il est habillé d'un caftan de couleurs pastelles, décoré de motifs pseudo-coufiques. Il porte une coiffe trapézoïdale qui lui couvre une partie de la chevelure qui est aussi ornée de motifs pseudo-coufiques. Il avance les mains en prière vers la Vierge. L'inscription permettant de l'identifier est au féminin, ce personnage est donc une femme.

Un archange de grande dimension succède à cette première laïque. Il porte un loros croisé, son nimbe est décoré de motifs crénelés, il est ailé15. Son visage est martelé mais il est possible d'observer les volutes formées par ses cheveux. Il porte de la dextre un bâton rappelant sa fonction d'intercesseur ou la lance qui évoque sa fonction de protecteur.

A la gauche de l'archange, deux personnages sont tournés vers lui. Habillés d'un vêtement qui pourrait être soit un caftan soit une armure - les motifs imitant, semble t-il, des mailles -, ils sont coiffés cette fois de turbans recouvrant entièrement leur chevelure. Le premier, accolé à l'archange, est barbu. Le second personnage est beaucoup plus difficile à étudier car la fresque, à cet endroit, est très abîmée ; on ne distingue qu'une partie de son vêtement et un fragment de sa coiffe.

La scène de dévotion continue sur une partie de la paroi ouest et semble s'interrompre au niveau de la porte d'entrée. Deux derniers personnages devaient

14) Une inscription permet de l'identifier.

15) Sur les archanges portant l'habit impérial : Jolivet-Lévy $2002: 121-128$. 


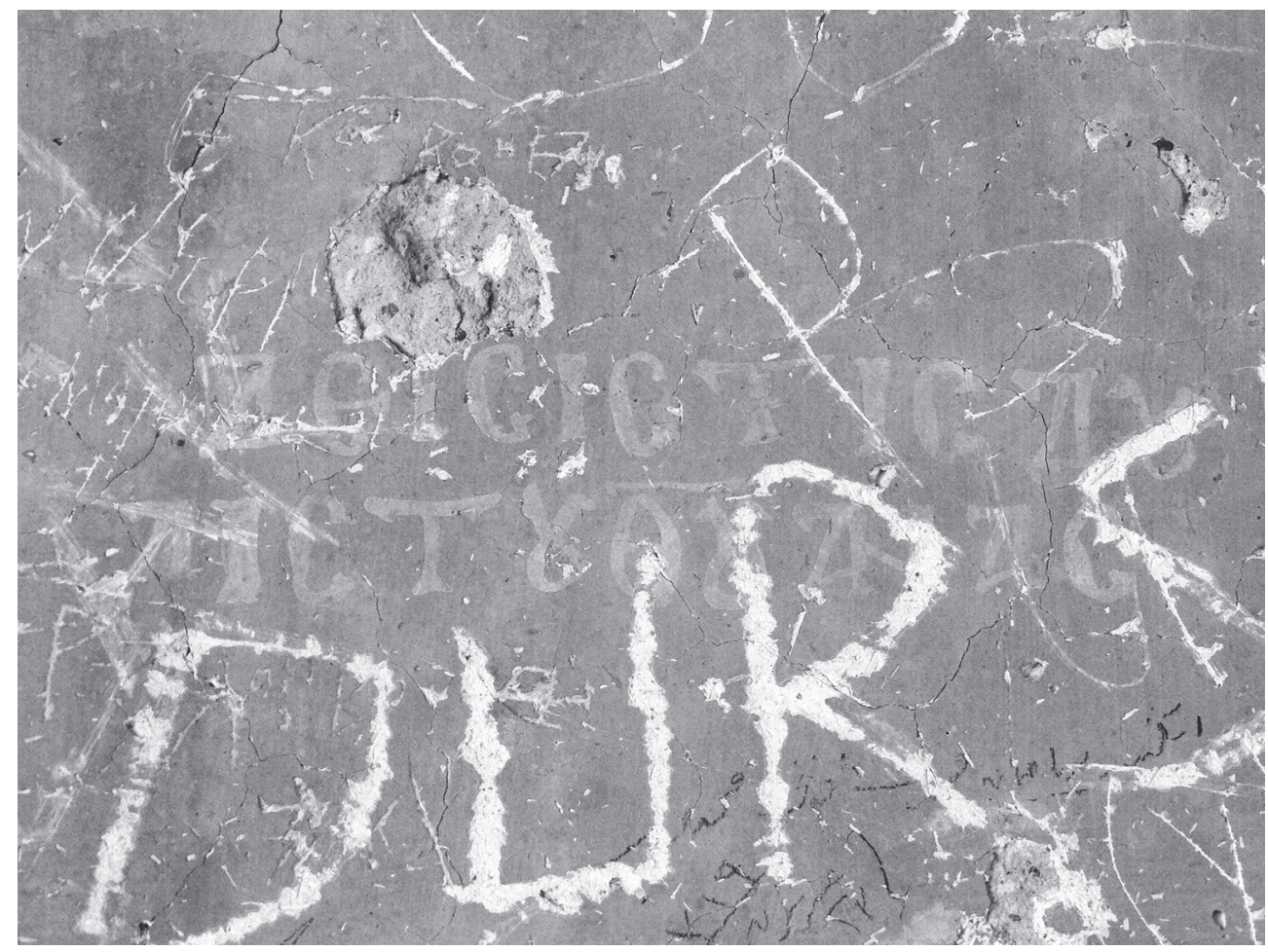

Fig. 9 : Inscription $n^{\circ} 2$.

être représentés. Egalement très endommagés, les fragments de fresque permettent cependant de distinguer leurs habits décorés des mêmes motifs - stylisation d'une armure - que le personnage situé à proximité de l'archange. Des fragments de leurs coiffes et quelques lettres sont visibles.

Cinq inscriptions peintes en blanc complètent cette scène de dévotion et permettent d'identifier certains personnages représentés :

Inscription $\mathrm{n}^{\circ} 1$, à droite de la tête de la Vierge sur une ligne :

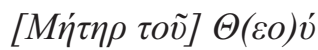

La mère de Dieu devait être désignée par les monogrammes traditionnels $M P \Theta Y$ cependant la deuxième partie du nom sacré @eov́ est le seul conservé.

Inscription $\mathrm{n}^{\circ} 2$, au-dessus de la coiffe du premier personnage à gauche sur deux lignes (Fig. 9) :

\footnotetext{
$\Delta \varepsilon ́ ı \iota \iota \tau \tau \iota \varsigma \delta(o v ́)$

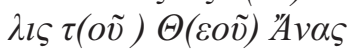

"Prière de la servante de Dieu An(n)a"

Cette formulation de la prière n'est pas la plus courante $^{16}$. Une sainte moniale Anna est représentée dans les églises de Kılıçlar Kilise, Meryemana et Karabaş Kilise et Elmalı Kilise où son nom est écrit "Ana"17.

Inscription $n^{\circ} 3$, de part et d'autre de la tête de l'archange :

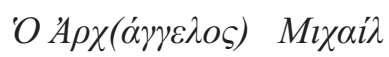

L'archange Michel est identifié grâce à son monogramme écrit à l'aide d'une ligature des graphèmes AP. Le X, de plus petite dimension, est située audessus de cette ligature.

Inscription $n^{\circ} 4$, au-dessus du turban du deuxième laïc, sur deux lignes. L'inscription est en partie lacunaire (Fig. 10) :

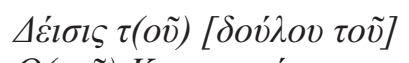

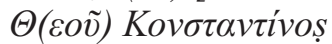

16) Des prières de ce type se lisent dans les églises de Karanlık, Çarıklı, Sainte-Catherine, l'église des Stratilates de Mavrucan et à Karabaş : Jerphanion 1928: I 396, 398, 458 et 475 et Jerphanion $1936:$ II 237 et 336-340. II 501.

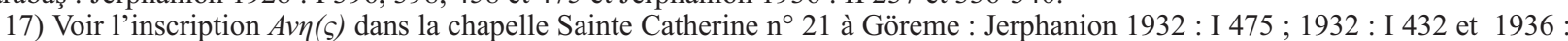




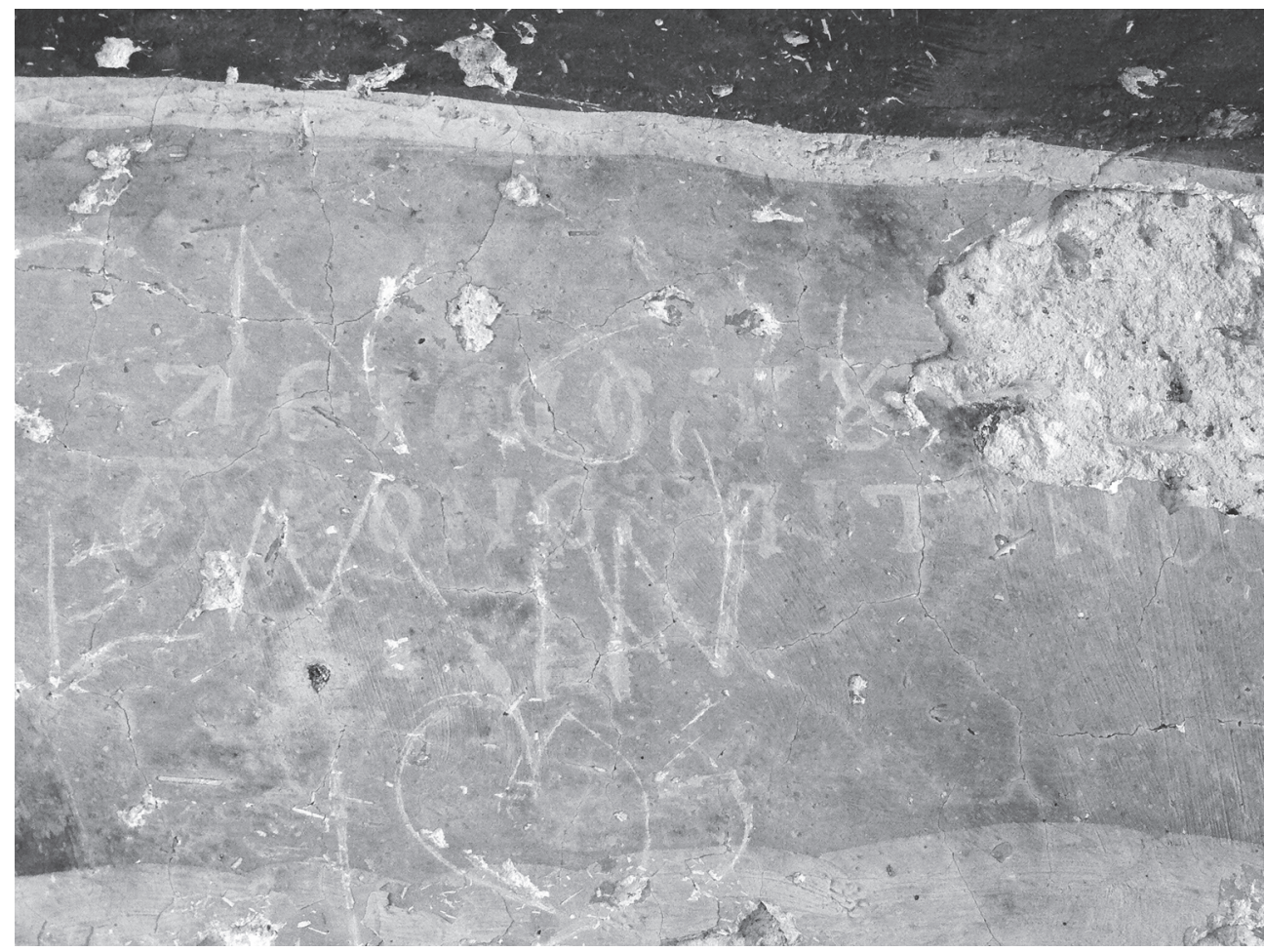

Fig. 10 : Inscription $n^{\circ} 4$.

\section{"Prière du serviteur de Dieu Constantin"}

Dans sa formulation, elle est identique à la première mais est au masculin. Le nom de Constantin est très répandu dans l'Empire byzantin. Cependant, seule une autre prière à Eğritaş Kilise est adressée par un Constantin ${ }^{18}$.

Inscription $\mathrm{n}^{\circ} 5$, entre le deuxième et le troisième laïc, sur quatre lignes (Fig. 11) :

$$
\begin{aligned}
& \Delta \varepsilon \dot{\varepsilon ́} \sigma l \varsigma \\
& \tau(o \tilde{v})[\delta](o v ́)[\lambda](o v) \\
& \tau(o \tilde{v}) \Theta(\varepsilon o \tilde{v}) N i \kappa i \\
& \tau \\
& {[o v]}
\end{aligned}
$$

"Prière du serviteur de Dieu Nikitas"

Selon l'organisation des lettres, le nom de Nıкท́ $\alpha_{\varsigma}$ paraît être le seul possible. La première lettre du prénom semble former un $\mathrm{N}$ puisqu'un morceau de la barre oblique ainsi que la verticale sont visibles ${ }^{19}$. Le A devait se situer sur une cinquième ligne.
L'homogénéité de l'orthographe ainsi que la façon d'écrire laisse penser que ces cinq inscriptions sont de la même main. Le peintre a utilisé exclusivement des onciales ; il emploie des vocalismes qui se manifestent par le remplacement de l' $\Omega$ par un $O$ et un iotacisme récurrent remplaçant le $\mathrm{H}$ par un $\mathrm{I}^{20}$. Les abréviations sont utilisées pour les nomina sacra ainsi que pour la combinaison de lettres ov qui s'écrit $\gamma$.

La partie du mur ouest, à la gauche de la porte est complètement détruite. Quelques restes d'enduit indiquent qu'elle devait être peinte, comme le reste de l'église.

La scène se développant sur la paroi nord de la nef est également en très mauvais état de conservation (Fig. 12). Quelques fragments de nimbe indiquent que deux personnages nimbés de grandes dimensions étaient représentés à proximité de deux autres dont il ne reste que l'esquisse.

Les trois premiers personnages les plus à l'Ouest sont manifestement des saints dont l'identification est impossible. Le dernier individu pose davantage

18) Thierry $1963: 70$.

19) Cette lettre ne peut pas être un $\mathrm{H}$.

20) Ces problèmes épigraphiques avaient déjà été soulevés par G. de Jerphanion au fil de son étude sur les églises rupestres de Cappadoce et approfondis dans une étude de cas par G. Kourtzian : Jolivet-Lévy 2002 : 135-176 et plus spécifiquement : $145-151$. 


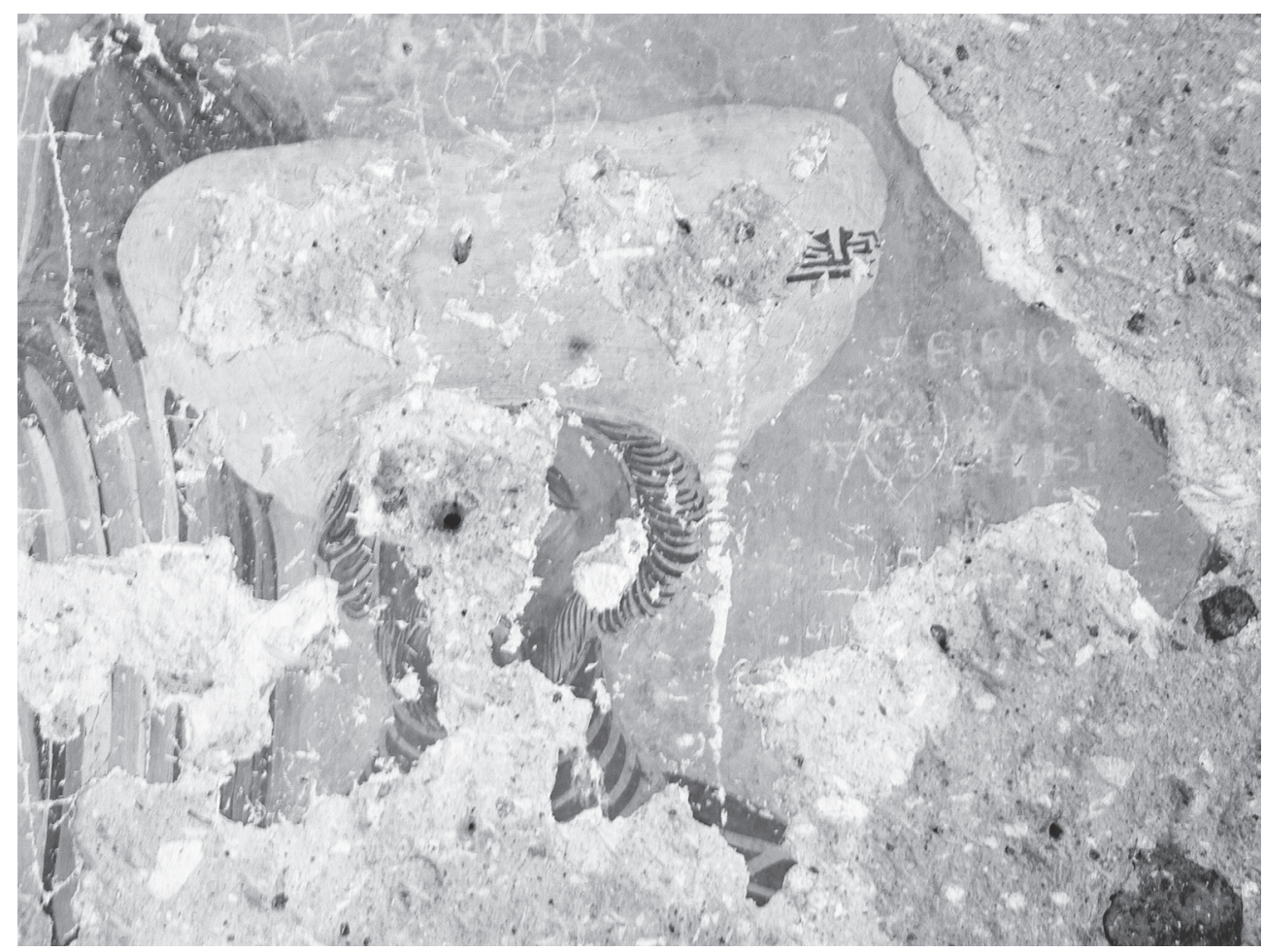

Fig. 11 : Inscription $n^{\circ} 5$ et figure du laïc Constantin.

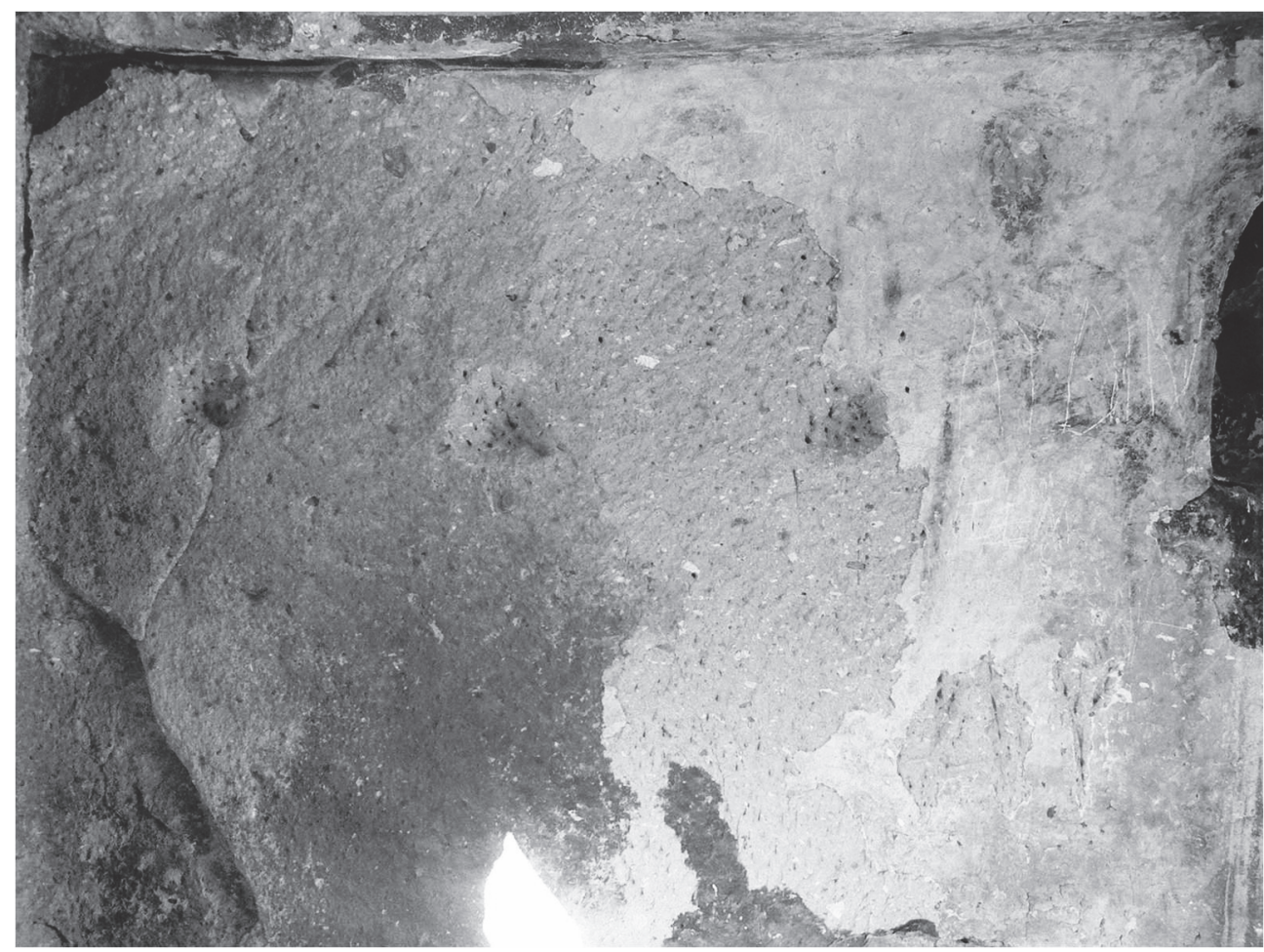

Fig. 12 : Déisis (?) paroi nord de la nef. 


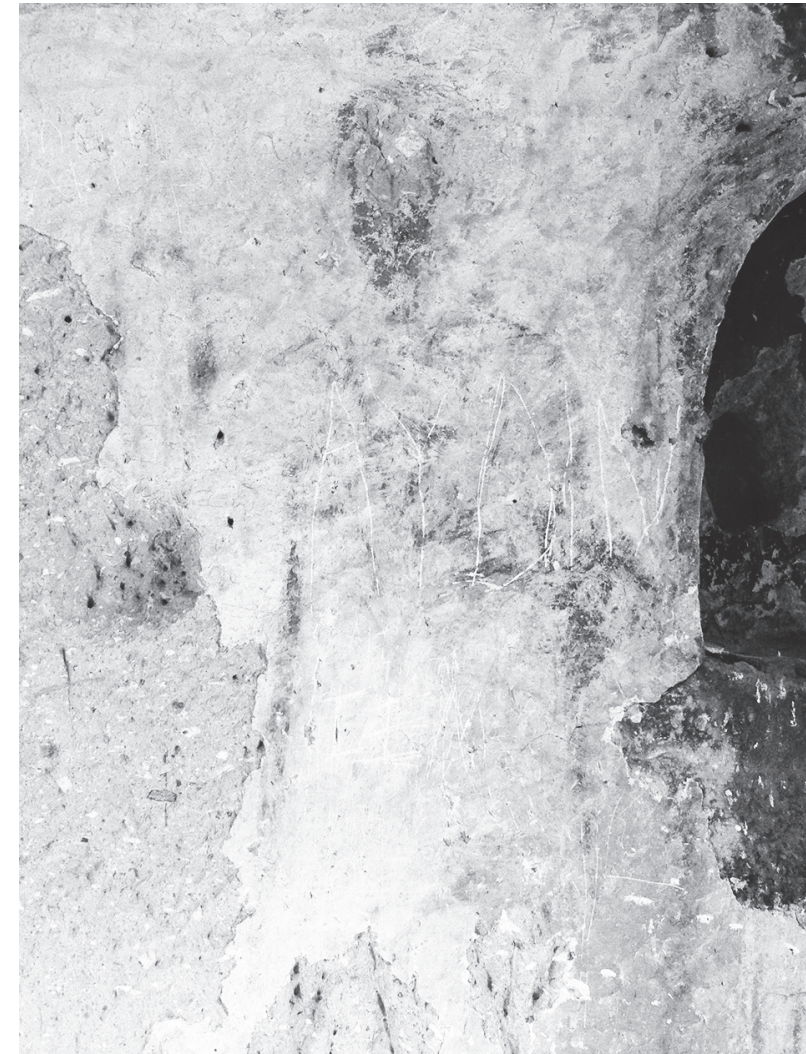

Fig. 13 : Détail du personnage au Nord de la Déisis (?).

de problème. Nous l'avions dans un premier temps comparé aux deux laïcs du mur sud. Son vêtement rappelle celui de Constantin, il paraît tourné de trois-quarts en avançant les mains vers le reste des protagonistes et semble de plus petite taille que les trois autres personnages nimbés. La scène représentait une déisis dans laquelle un dernier donateur était peint $^{21}$. Cette scène peut être mise en relation avec une scène de dévotion en Cappadoce, comme le prouve la mise en scène à l'église de Çarıklı de Göreme $^{22}$. Cependant l'état du panneau est tel qu'il pourrait s'agir également de la représentation d'un Saint portant un omophorion ou un vêtement décoré d'un galon au niveau du col (Fig. 13).

La niche à fond plat, dite de prothèse, est placée au Nord-Est de l'église et était également peinte. Le buste représentait très certainement un saint dont on distingue encore le nimbe et une partie du visage. Un fragment de vêtement pourrait suggérer la présence d'un omophorion permettant d'identifier ce saint à un évêque. Au-dessus de cette niche, des rinceaux forment un cartouche sur le ressaut de la voûte. Cette décoration, cantonnée à cette partie de l'église, devait mettre en valeur l'emplacement privilégié de la niche. Sur la partie nord de l'arc triomphal, on observe des médaillons où des bustes de saints devaient être représentés mais leur état de conservation ne permet pas de les détailler davantage.

\section{DESCRIPTION DE LA SALLE ADJACENTE}

Une ouverture effectuée dans la partie orientale du mur nord et détruisant une partie de la niche de prothèse donne sur une salle qui, au départ, ne devait donc pas communiquer avec la nef. Cette salle est en grande partie démolie, seules sa paroi ouest et une partie de son plafond subsistent.

Un archange représenté dans un panneau bien délimité par un liserai rouge est conservé à proximité de la porte (Fig. 14). La tête de l'archange est martelée. Il porte un loros croisé gemmé de couleur jaune et semble tenir de la dextre une lance. Aucune inscription ne permet de l'identifier.

Ce panneau se différencie du reste du décor par un aspect plus grossier et massif. On l'observe dans la facture des ailes. La palette pastelle est remplacée par l'emploi de couleurs jaune et marron, plus criardes.

\section{HYPOTHESES SUR LA DATATION DE L'EGLISE}

Plusieurs indices permettent de dater la phase de creusement, la campagne de décoration de la salle adjacente et celle de la chapelle des Donateurs, en se basant notamment sur une comparaison avec l'église de Karabaş.

La présence d'une niche de prothèse dans la partie orientale de la paroi nord de la nef permet de dater le creusement de l'église avant l'évolution du rite de prothèse ${ }^{23}$. Ce changement de rite induit, en effet, la migration de la niche de la nef vers l'abside visible en Cappadoce grâce au caractère rupestre des édifices. Cette migration s'observe dans les églises cappadociennes à partir du $10^{\mathrm{e}}$ siècle. Nous pensons donc que la chapelle des Donateurs a été creusée avant le milieu du $10^{\mathrm{e}}$ siècle. 


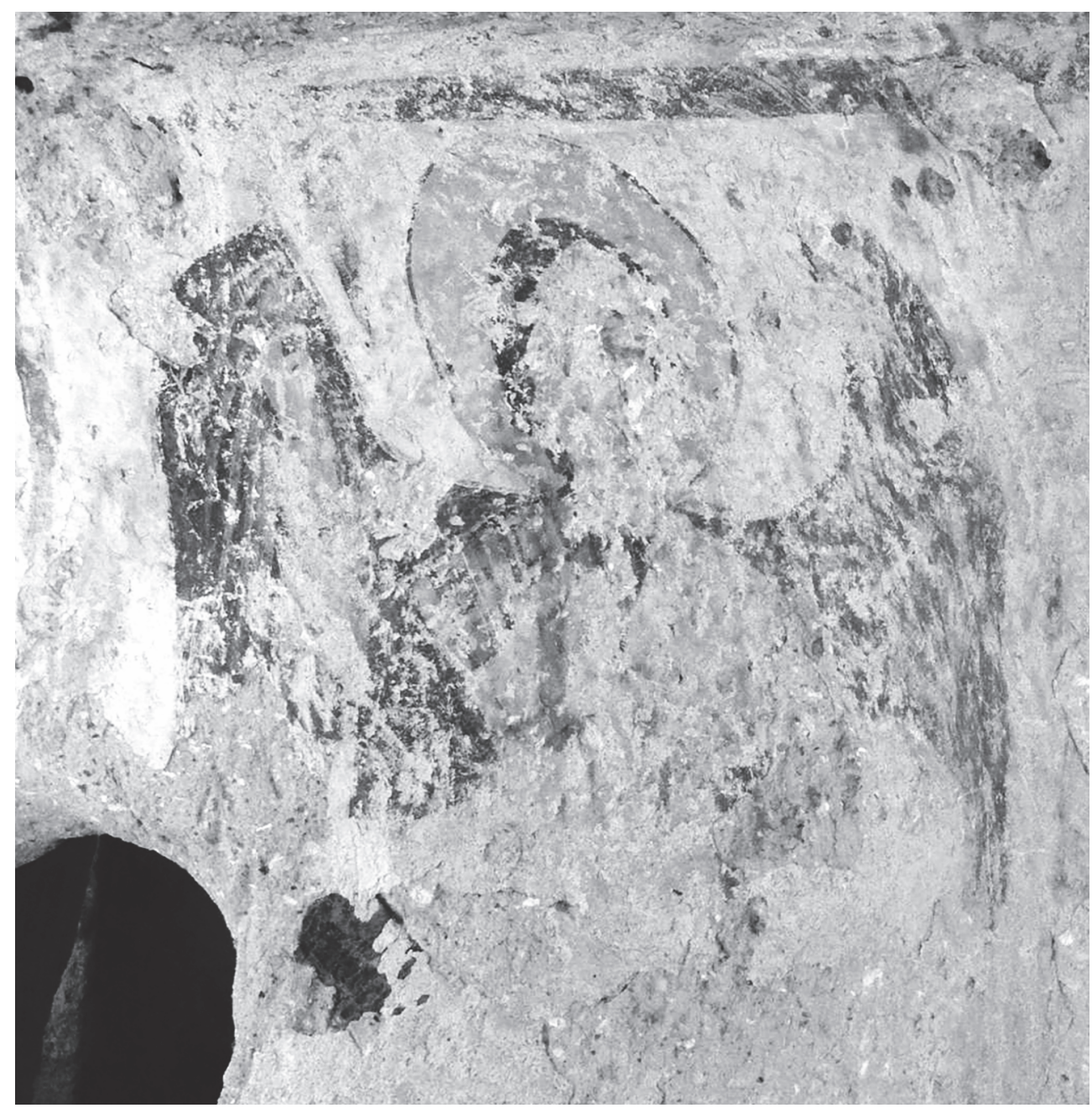

Fig. 14 : Archange, paroi ouest de l'annexe de la chapelle.

La première campagne est représentée par le panneau de la salle adjacente qui contraste avec le reste du décor de la chapelle tant d'un point de vue de la facture que des couleurs. Cette première campagne peut être rapprochée stylistiquement du décor du narthex de l'église de Nicéphore Phocas à Cavușin et de l'église des Saints-Apôtres à proximité de la ville de Mustafapaşa. L'apparente massivité de l'archange et le traitement des détails du loros rappellent les archanges représentés dans ces deux églises, toutes deux datées du $10^{\mathrm{e}}$ siècle $^{24}$.

L'emploi des couleurs jaune et ocre dans les peintures cappadociennes semble être un indice de datation haute. On retrouve cette palette dans la pre- mière phase de décoration de l'église de Karabaş (détail apparent dans la nef et dans l'un des parekklèsia), dans l'église de Nicétas (Üzümlü Kilise) du vallon de Kızıl Çukur et dans l'église Saint-George de Zindanönü Dere. Ces trois décors peints sont datés entre le $8^{\mathrm{e}}$ et le $9^{\mathrm{e}}$ siècle $^{25}$. On doit toutefois souligner qu'à Soğanl1, ces couleurs apparaissent dans le décor peint de l'église de Gök Kilise, daté du début du $10^{\mathrm{e}}$ siècle $^{26}$. Il est donc tentant de situer ce décor dans la première moitié du $10^{\mathrm{e}}$ siècle.

La seconde campagne de décoration concerne la chapelle à proprement parler. Les motifs récurrents de volutes et l'emploi du pseudo-coufique permettent de situer l'ensemble du décor à la période médiévale ${ }^{27}$. 
De même, on observe dans les inscriptions la présence récurrente d'apices sur les lettres $A, \Sigma C, \Delta$ et $T$, phénomène courant à partir du $10^{\mathrm{e}}$ siècle $^{28}$.

Le type de formulation utilisé dans les prières semble être employé uniquement dans les églises cappadociennes à partir du $11^{\mathrm{e}}$ siècle. De même, le monogramme de l'archange Michel paraît caractéristique du $11^{\mathrm{e}}$ siècle $^{29}$. L'organisation du décor est également un indice et doit être comparée aux églises du $11^{\mathrm{e}}$ siècle, notamment les églises à colonnes du site de Göreme. Le peintre ne s'attache plus à suivre l'ordre chronologique de la Vie du Christ mais tend à transmettre un message dogmatique ${ }^{30}$. Enfin, le style précieux des peintures de la chapelle pourrait permettre de préciser sa datation en la plaçant dans la seconde moitié du $11^{\mathrm{e}}$ siècle ap. J.-C. ${ }^{31}$

Cette dernière hypothèse paraît confortée grâce à l'étude du couvre-chef de la dédicante Ana. Les décorations pseudo-coufiques du turban peuvent être mises en relation avec la coiffe d'Eudocie dans l'église de Canavar Kilise datée de la seconde moitié du $11^{\mathrm{e}}$ siècle $^{32}$. Sa forme trapézoïdale s'apparente davantage à celle d'Irène Gabras représentée dans une miniature du manuscrit Petrop. gr. 291 daté de $1067^{33}$. Enfin, le titre donné à Siméon, formulé uniquement sur le site de Soğanlı apparaît dans le décor de Karabaş Kilise datée précisément des années 1060-1061. Il semble donc que cette campagne de décoration puisse être placée aux alentours de $1060^{34}$.

\section{REFLEXION SUR LA FONCTION DE L'EGLISE ET SES COMMANDITAIRES}

Cette chapelle retient notre attention à plusieurs titres : elle est le seul exemple à notre connaissance qui possède une scène de dévotion d'aussi grande dimension, se déployant sur deux parois. En Cappa- doce, les donateurs sont le plus souvent associés à une scène en particulier ou à une figure isolée. Dans le cas de notre église, la mise en scène est en lien avec sa fonction; de même, la chapelle pourrait être un nouveau témoignage du patronage réalisé par la famille de Sképidès, élites rurales cappadociennes à Soğanl ${ }^{35}$.

Les scènes de la voûte de la chapelle - bien que leur identification ne soit pas assurée - ne suivent pas une organisation chronologique. L'Annonciation, en effet, termine le cycle. De même, la Dormition s'intercale entre la Présentation au Temple et la Crucifixion. Ce 'désordre' apparent est courant en Cappadoce à partir du $11^{\mathrm{e}}$ siècle et s'explique par la volonté de transmettre un message particulier au fidèle $^{36}$. L'association Nativité/Annonciation et Présentation au Temple/Crucifixion semblent rappeler le mystère de l'Incarnation. Dans chaque binôme, la double nature du Christ est suggérée.

La mise en avant de la laïque An(n)a, représentée entre la Vierge et l'Archange Michel est un indice de la fonction de l'église. La présence récurrente de la Vierge dans les scènes de la voûte et dans le décor de la nef -Nativité, Présentation, Dormition, Crucifixion, Annonciation, scène de dévotion et peut-être de déisis - prouve l'importance accordée à la figure féminine. La symbolique du Salut magnifiée par l'organisation dynamique binaire des scènes de la voûte ne doit pas non plus être oubliée. Enfin, la représentation de la Dormition à l'Ouest de l'église en face de l'abside au-dessus de l'entrée du naos fait référence à l'entrée de la Théotokos dans le royaume de Dieu comme l'âme renait dans le royaume de Dieu grâce au Salut ${ }^{37}$. Les notions de Salut, de Renaissance et de Résurrection symbolisées dans le décor incitent à identifier cette chapelle comme funéraire ${ }^{38}$.

28) Jolivet-Lévy $2002: 145$ et note 77

29) Jerphanion 1942 : II 530 à l'entrée paléographie.

30) Thierry $1975: 85$.

31) Thierry $1967: 154$.

32) Jerphanion 1936 : II 363 est plus précis et compare l'église à celle de Karabaş Kilise en plaçant l'ensemble du décor autour de 1060 ; datation reprise par Parani 2003 : planche 86 fig. c.

33) Parani 2003 : planche 86 fig. d.

34) L'observation des peintures de la nef n'a pas permis de constater la présence d'une campagne précédente. Il semble donc que les deux monuments (église et salle adjacente) furent décorés de manière autonome.

35) Cette famille a décoré les églises de Karabaş, Canavar et Geyikli. Jerphanion 1936 : II 334-335, 363-364, 371-372 ; Thierry 1975 : 96 note 116 ; Jolivet-Lévy 2012 : 152-155. Le terme d'élite rurale, encore peu employé dans les études byzantines, se justifie pour la famille Sképidès : Voir Kaplan $2012: 299-312$.

36) Jolivet-Lévy $2002: 296$ et 366.

37) Jolivet-Lévy 1991 : 307. On retrouve l'image du Salut permettant d'atteindre le royaume de Dieu dans Jean 3,3.

38) Deux hypothèses pourraient être avancées : une première verrait dans le personnage d'Ana, la défunte pour qui l'église a été décorée. Une seconde serait d'identifier le personnage à proximité de la Déisis comme le défunt, sa position à proximité de la scène favorisant son intercession auprès du Christ. 
L'importance de la figure mariale et la situation de la Vierge trônant à proximité de l'abside pourraient suggérer que l'église lui était dédicacée ${ }^{39}$.

En effet, Uune seconde fonction de l'église doit être mise en relation avec le patronage des Sképidès à Soğanl1. La narration de l'histoire du Salut semble mettre en avant le rituel eucharistique, rite essentiel dans la religion chrétienne, car il permet le rapprochement entre le fidèle et le Créateur ${ }^{40}$. Tout concourt, semble t-il, à symboliser le Salut de l'âme par la pratique de la prière.

La place prépondérante de la scène de dévotion et le nombre important de suppliants représentés dans l'église, toujours associés à leur supplique semblent l'attester ${ }^{41}$. De même, l'image de l'intercesseur est très présente dans le décor. On l'observe par l'importance donnée à la Vierge située en bonne place à proximité du bêma, à la représentation de l'archange Michel en habit impérial tenant sa lance ainsi que par la scène de Déisis de grande taille ${ }^{42}$. Le choix d'intégrer la Présentation au Temple dans le décor de la voûte, pour une église de si petite dimension, appuie cette hypothèse. Cette scène est peu courante et sa représentation est souvent associée aux grands cycles développés de la Vie du Christ ${ }^{43}$. Sa présence pourrait rappeler, outre le Salut de l'âme et la double nature du Christ, la prière des fidèles durant le transfert des oblats.

Le décor de cette église semble être réalisé comme un écrin afin de commémorer la prière d'An(n)a, Constantin et Nicétas pour leur Salut. C'est pourquoi, nous pensons que cette église est également un psychikon ${ }^{44}$.

Cette hypothèse pourrait être confirmée par le lien saisissant qui peut être établi entre la chapelle des Donateurs et Karabaş kilise car on peut rapprocher la représentation de la Nativité de ces deux églises par leur iconographie, Joseph à droite et le bain de l'enfant à gauche, par la localisation de la scène à proximité de l'abside au Sud, et par la succession entre Nativité et Présentation au Temple. De plus, la datation du décor l'inscrit dans le mouvement de travaux de restauration qu'ont engagé les Sképidès dans les églises de Karabaș, Canavar et Geyikli. Sa situation géographique, enfin, entre les deux églises de Karabaş et de Canavar est un élément important.

La chapelle des Donateurs paraît être l'illustration parfaite d'une fondation de laïcs réalisée pour le salut de leur âme. L'idée même de psychikon est confirmée par la dédicace de 1060-1061 dans l'église de Karabaș "Cette église a été embellie par les soins de Michel Sképidès, protospathaire, Catherine, moniale, et Nyphon, moine, sous l'empereur Constantin Douka, l'année 6569, indiction 14. Vous qui lisez, priez pour eux le Seigneur. Amen"45. Nous pensons que cette famille fait partie des élites rurales dont parle M. Kaplan plutôt qu'une grande famille cappadocienne comme les Phocas ou les Maléïnoi. Cette hypothèse se dessine au regard de l'action très localisée de la famille, qui n'apparaît pas dans d'autres sites cappadociens. De plus, le site de Soğanlı en Cappadoce, mal identifié, semble être davantage un village qu'une ville à l'époque médiévale $^{46}$. Les remplois observés dans le village actuel proviennent de sites des environs et aucune structure bâtie de l'époque médiévale n'a été découverte sur le site même ${ }^{47}$.

\section{LE CONTEXTE GEO-POLITIQUE DU SITE DE SOĞANLI}

De nombreux chercheurs situent le site de Soğanlı en Cappadoce rupestre ${ }^{48}$. Cette dénomination, d'une zone couverte de roches volcaniques tendres - l'ignimbrite - où sont creusés de nombreux tombeaux et églises, pose un problème de géographie historique. Il faut donc reprendre la définition administrative et religieuse de la zone rupestre pour tenter de localiser le site.

L'administration byzantine connait un changement administratif majeur mais long et discontinu, marqué par la disparition progressive des provinces au profit

39) Jerphanion 1936, II 307 note 1 et 2 et 321 ; Jolivet-Lévy $2001:$ 382-383.

40) Walter $1982: 188$.

41) Les fragments sur le mur ouest prouvent que les deux laïcs étaient également accompagnés d'une prière.

42) Jolivet-Lévy $2002: 450$ et note 15.

43) Jolivet-Lévy, $2001: 194$.

44) Pour la définition de psychikon: Lemerle 1977 : 101 note 81 ; Kaplan 1983 : 72 note 8.

45) Traduction tirée de Thierry 2002 : fiche 47.

46) L'identification à Soandos n'est pas certaine.

47) Lemaigre Demesnil $2002: 43$ note 26 et 27.

48) Les titres sont évocateurs : G. de Jerphanion 1928-1942: Une nouvelle province de l'art byzantin: Les églises rupestres de Cappadoce; C. Jolivet-Lévy 1991 : Les églises byzantines de Cappadoce : Le programme iconographique de l'abside et de ses abords ; L. Rodley 1985 : Caves Monasteries of Byzantine Cappadocia; N. Thierry 2002 : La Cappadoce de l'Antiquité au Moyen Age. Seuls F. Hild et M. Restle (1981) sont plus prudents et préfèrent parler de Kappadokien (Kappadokia, Charsianon, Sebasteia und Lykandos) mais ils parlent de "kappadokien Höhlenkirchengebiet" dans la notice d'Hagios Prokopios (Hild et Restle 1981 : 263). 
de thèmes à partir du $7^{\mathrm{e}}$ siècle, dont témoignent deux ouvrages rédigés dans le cercle intellectuel de Constantin Porphyrogénète (913-959) ${ }^{49}$. D'origine militaire puisqu'il s'agit d'une unité de soldat dans l'armée, le terme $\Theta \varepsilon ́ \mu \alpha$ prend au $10^{\mathrm{e}}$ siècle un sens territorial marqué comme en témoigne le De Velitationes de Nicéphore Phocas $^{50}$. Deux thèmes nous intéressent particulièrement dans cette étude, il s'agit des thèmes de Cappadoce et de Charsianon ${ }^{51}$.

On connait un stratège de Cappadoce mentionné dans les récits portant sur les événements des années $830^{52}$, le thème administratif est attesté pour sa part aux $9^{\mathrm{e}}$ et $10^{\mathrm{e}}$ siècles $^{53}$. Le Charsianon semble devenir un thème à la fin du $9^{\mathrm{e}}$ siècle ${ }^{54}$.

Dans le De Administrando imperio, l'auteur souligne qu'à l'époque de Léon VI (886-912), la tourma de Kasè et les topoteresia de Nyssa et de Césarée sont transférées de la province de Cappadoce à celle du Charsianon ${ }^{55}$.

L'identification des deux topoteresia ne pose aucune difficulté puisque Nyssa est bien attestée dans les sources comme Césarée, connue auparavant par le nom de Mazaka. Par contre, l'identité de la tourma de Kasè pose problème. W. M. Ramsay pensait y voir la réunion des villes de Tyane et de la plaine de Venasa ${ }^{56}$. Cependant une notice épiscopale datée du $10^{\mathrm{e}}$ siècle mentionne une $K \alpha ́ \sigma \eta$ associée à la ville d'Ariaratheia ${ }^{57}$. On sait que cette ville se situait depuis la fin du $4^{\mathrm{e}}$ siècle en province d'Arménie II et non plus en Cappadoce ${ }^{58}$. La ville est bien à l'Est de Césarée et non pas comme le souligne Ramsay à proximité de Tyane.
Dans le De Thematibus, l'auteur définit davantage le nouveau thème de Cappadoce ${ }^{59}$. Ce long passage mêle à la fois des données anciennes reprises de Strabon et des informations plus récentes issues de sources tardo-antique. L'auteur désigne le thème de Cappadoce comme la $\mu \iota \kappa \rho \dot{\eta}$ К $\alpha \pi \pi \alpha \delta o \kappa i \alpha$, qu'il oppose à la Grande Cappadoce. Il la définit ainsi : "Limitrophe des Lycaoniens et du Taurus, la Petite Cappadoce, portant aujourd'hui le nom de thème /

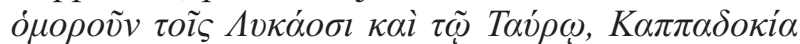

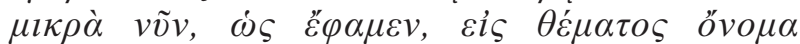
$\chi \rho \eta \mu \alpha \tau i \zeta o v \sigma \alpha " 60$. Un peu plus loin, à la manière des géographes de l'époque antique, il liste les villes rattachées à cette petite Cappadoce qu'il nomme Cappadoce deuxième : "Huit cités de la Cappadoce deuxième sont soumises à un gouverneur Tyane, Phaustinoupolis, Kybistra, Nazianze, Sasima, Parnassos, Rhegedôra, Môkissos et la forteresse appelée

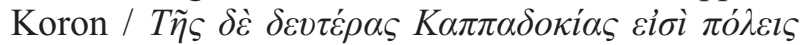

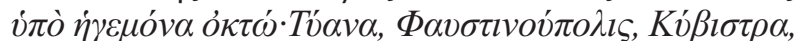

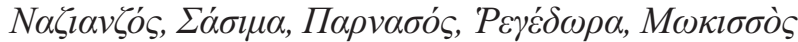

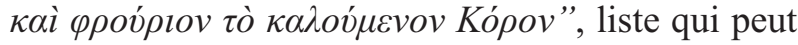
être rapprochée du Synèkdémos de Hiéroclès datée du $6^{\mathrm{e}}$ siècle $^{61}$.

Dans le cas du thème de Charsianon qu'il définit comme la "partie inférieure de la Cappadoce", il souligne : "Il y a quatre cités remarquables dans la première province, Césarée la métropole [...] la deuxième ville est Nyssa, la troisième Therma, la

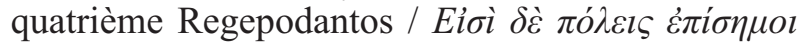

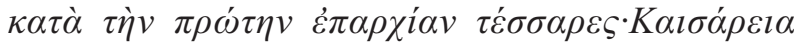

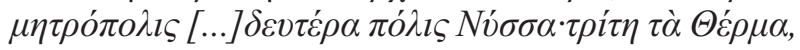

49) Pertusi $1958: 1$ citant Rambaud 1870 : 175 : “La géographie du Xe siècle, dit-il, nous met en présence d'une terminologie administrative complètement différente de la Notitia (Dignitatum utriusque imperii)". Pour le début du processus de réformes administratives : Pertusi $1958: 2$ et 39-40.

50) NICEPHORE PHOCAS De Velitatione : 240. La mention de stratège dans les listes de préséances dès le $9^{\mathrm{e}}$ siècle ap. J.-C. paraît désigner une fonction administrative : Listes : 341 .

51) La bibliographie sur cette 'réforme' territoriale est pléthorique et contradictoire. Le bilan bibliographique sur l'administration byzantine de 641 à 1204 de J.-C. Cheynet (2006a : XXVI-XXIX) énumère les ouvrages de références. Récemment, s'appuyant sur le témoignage des sceaux, J. -C. Cheynet (2010: 1 note 1) met en exergue les discussions autour de la réforme thématique et s'interroge sur l'emploi du terme 'réforme' pour désigner le processus de création des thèmes.

52) NICEPHORE PHOCAS De Velitatione : 241 ; Listes : 48 et note 24 qui restitue une omission d'un stratège de Cappadoce. N. Oikonomidès se base, entre autre, sur une attestation de Théophane Continué, œuvre datée du $10^{\mathrm{e}}$ siècle : A. Berger, s.v. Iohannes et propose de placer la création du thème de Cappadoce en 830. S. Métivier (2008:444) conteste cette hypothèse et avance la fondation du thème dans les années 800 , sous le règne de Nicéphore ${ }^{\text {er }}(802-811)$.

53) La première attestation se trouve dans le traité de Philothée datant de 899 ap. J.-C. : Listes : 65, 101 lig. 11,105 lig. 3 et 137 lig. 26. Pour une reprise récente de la question : Métivier 2008

54) Listes : 45 atteste d'une kleisourie jusqu'en 873 ap. J.-C. Le stratège de Charsianon apparaît dans le traité de Philotée : 101 lig. 12,105 lig. 4 et 137 lig. 27.

55) De Administrando : $236 \S 50$ lig. 108-110.

56) Ramsay 1890: 250. Il semble que l'Oxford Byzantium Dictionnary s'appuie sur cette identification pour dessiner les frontières des thèmes de Cappadoce et Charsianon sur la carte qu'il propose à l'entrée Thema.

57) Notitia VII : 1, 112 ; Hild et Restle $1981: 202$; Moulet $2011: 81$.

58) HIEROCLES Synekdèmos 703, 12 ; Métivier $2005: 44$ et $65-66$ carte 2.

59) De Thematibus II B' : 63-66.

60) De Thematibus II B': 65 \$201. 49-51.

61) De Thematibus II B' : 65 § 21 lig. 62-65. 


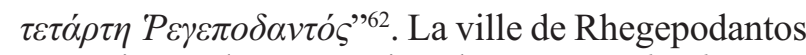
pourrait être la contraction du regio Podendos que l'on rencontre dans le Synekdémos ${ }^{63}$.

Enfin, toujours dans le De Thematibus, les limites de ce nouveau thème de Cappadoce sont décrites : "La Petite Cappadoce, qui prend aujourd'hui le titre de thème, celle qui est limitrophe de la Lycaonie et s'étend jusqu'à Césarée elle-même, s'élargit jusqu'au commencement des Bucellaires, aboutit à l'Est à Rhodentos elle-même, à la forteresse appelée Loulon

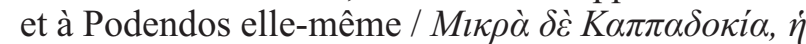

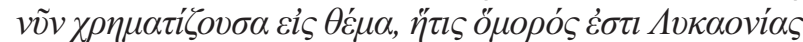

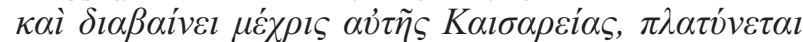

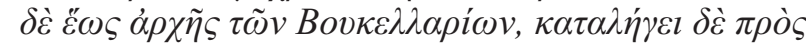

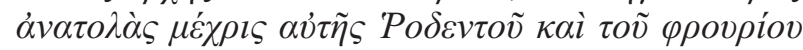

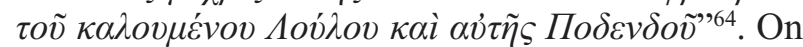
note que les frontières proposées par l'empereur sont les limites externes du nouveau thème de Cappadoce puisque Césarée est la nouvelle métropole du thème de Charsianon.

Ces deux sources illustrent l'évolution que connurent les anciennes provinces de Cappadoce I et II. La Cappadoce I semble amputée dès la fin du $9^{\mathrm{e}}$ siècle de sa partie sud-ouest. De même, les deux métropoles Césarée et Tyane - qui appartenaient respectivement à la Cappadoce I et la Cappadoce II chez Hiéroclès $\left(6^{\mathrm{e}}\right.$ siècle $)$ - continuent à être séparées.

Dans les Notitiae episcopatuum datées de la même époque que les écrits de Constantin Porphyrogénète $\left(10^{\mathrm{e}}\right.$ siècle), les notices VII, IX et $\mathrm{X}$ donnent des indications assez précises sur les cités suffragantes des métropoles de Césarée et de Tyane.

Dans ces trois notices, on ne retrouve pas les désignations de Cappadoce I et Cappadoce II. Elles apparaissent cependant, dans la notice I et III antérieures, datées du $8^{\mathrm{e}}$ siècle ${ }^{65}$. Ces deux appellations traduisent la marque d'un certain conservatisme, l'Eglise gardant l'appellation des anciennes provinces romaines pour désigner ses éparchies ${ }^{66}$. Toutefois, on remarque que l'éparchie de Cappadoce I a pour métropole Césarée comme le thème de Charsianon alors que l'éparchie de Cappadoce II contient la ville de Tyane - celle-ci n'est pas désignée comme métropole civile - comme pour le thème de Cappadoce. Une deuxième éparchie de Cappadoce II est mentionnée dans la notice III. Elle a pour métropole la ville de Môkissos, que l'on retrouve par la suite dans les notices de VII à $\mathrm{X}^{67}$.

Dans les listes des cités suffragantes de la notice VII, on pointe le fameux topononyme Kasè associé à l'éparchie de Cappadoce $\mathrm{I}^{68}$. D'autres villes correspondent à la liste donnée par Constantin Porphyrogénète : Césarée, Basilika Therma et Nyssa. De même, les villes appartenant au thème de Cappadoce semblent pouvoir être rapprochées de certains évêchés des deux Cappadoce II (Tyane et Môkissos) : Sasima, Phaustinopolis et Kybistra sont des évêchés suffragants de Tyane alors que Parnassos et Nazianze sont des cités suffragantes de Môkissos.

Le site de Soğanlı a été identifié à une station Soandos sur la voie de Tavium à Mazaka (l'ancienne Césarée) évoquée par Strabon ${ }^{69}$. Cette identification est fragile dans la mesure où le rapprochement entre le village de Soğanlı et Soandos est phonétique. On peut toutefois placer le site à proximité de la route joignant Césarée aux Pyles Ciliciennes qui se situent justement entre les éparchies de Cappadoce I et de Cappadoce II (Tyane) et entre le thème de Cappadoce et de Charsianon ${ }^{70}$.

Deux évêchés suffragants de Cappadoce I sont à remarquer : Hagios Prokopios et Sobessos issus tous deux de la notice VII ${ }^{71}$. Le premier, Hagios Prokopios, est identifié à la ville d'Ürgüp qui semble encore nommée Prokopion au début du $20^{\mathrm{e}}$ siècle $^{72}$. La détermination du deuxième toponyme est moins assurée puisqu'aucune preuve ne permet d'en valider sa localisation ${ }^{73}$. Matianè, évêché suffragant de Cap-

62) De Thematibus II B' : $65 \S 20-21$ lig. 58-62.

63) HIÉROCLÈS Synekdèmos 699, 3.

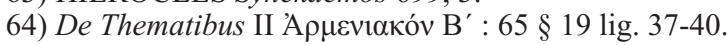

65) Moulet $2011: 45$ et 65 note 157.

66) Moulet $2011: 64$ et note 156

67) B. Moulet (2011 : 92) désigne cette éparchie comme la Cappadoce troisième ce qui ne me semble pas rendre compte de la dé-

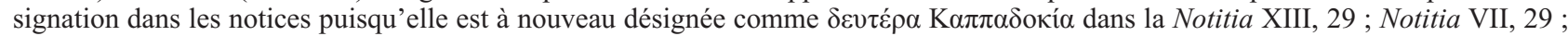
Notitia VIII, 30 ; Notitia IX, 29 ; Notitia X 29.

68) Notitia VII

69) STRABON Géographie: XIV.2, 29. Hild et Restle $1981: 282$. L'identification de la ville n'est pas certaine et reste discuter : en dernier lieu Zgusta $1984: 579$. On notera que le village était appelé Soğanlı dès le $19^{\mathrm{e}}$ siècle comme en témoigne le voyageur J. Mcdonald Kinneir (1818 : 177) qu'il appelle "Sone-Henge" ce qui prouve que son caractère grec ne semble pas conserver par sa toponymie.

70) Hild $1979: 119$ carte 111.

71) Notitia VII 1, 115-116.

72) Hild et Restle $1981: 263$.

73) Hild et Restle $1981: 285$. 


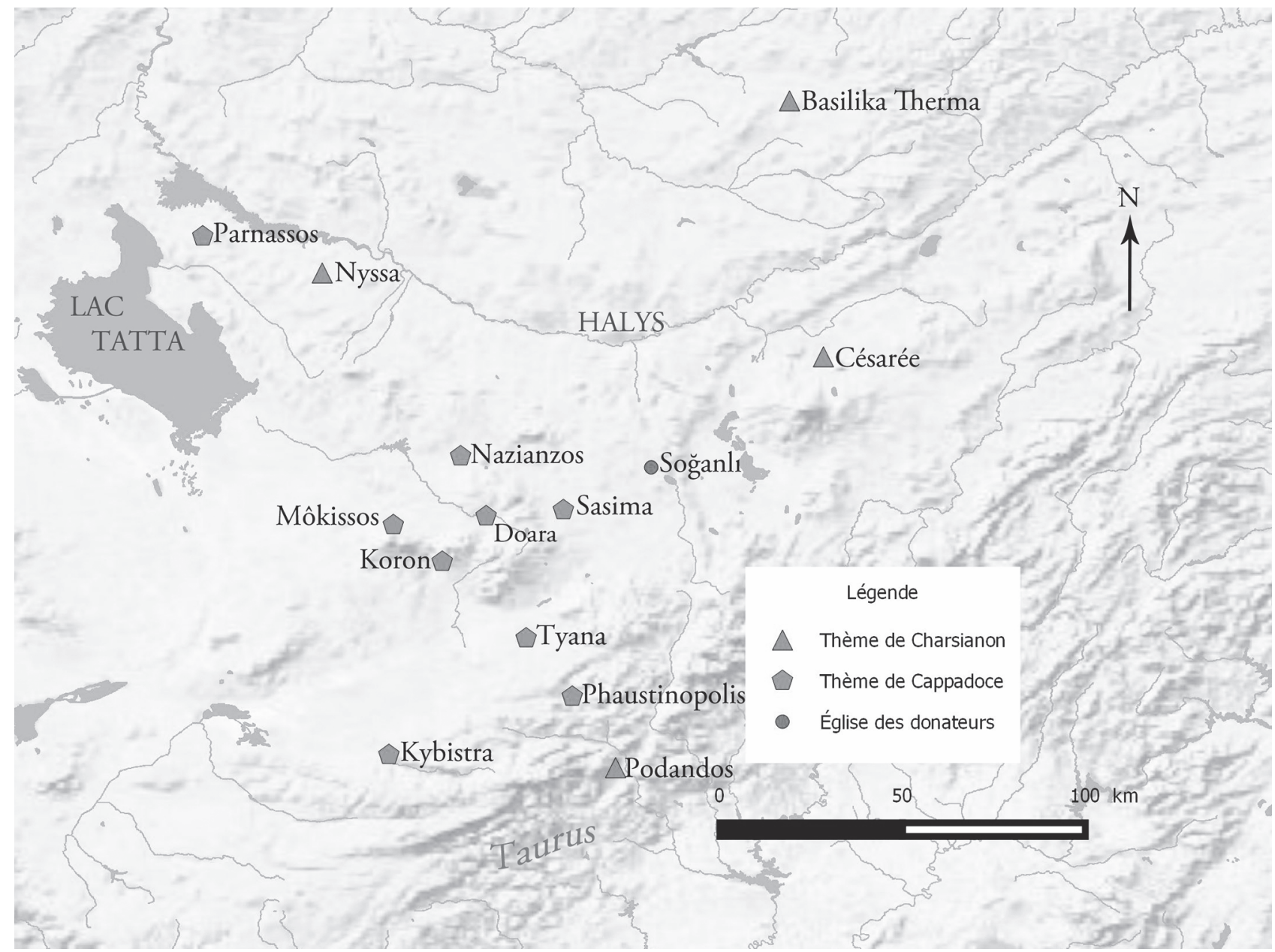

Carte 1 : Carte de la distribution des villes appartenant aux thèmes de Cappadoce et du Charsianon.

padoce II dont la métropole est Môkissos, est attesté dans la notice $X$ et se situe également sur ce même parcours ${ }^{74}$. Comme pour Sobessos, l'identification de Matianè au quartier Avcilar de la ville actuelle de Göreme ne semble pas fondée sur des preuves so$\operatorname{lides}^{75}$. Cette route aboutit, enfin, à la ville de Podandos associée dans les Notitiae à l'éparchie de Cappadoce I.

La zone rupestre ne paraît pas avoir connue d'évolutions majeures du point de vue de son administration religieuse et civile entre les $10^{\mathrm{e}}$ et $11^{\mathrm{e}}$ siècles $^{76}$.
En reprenant les informations données dans le De thematibus et le De administrando, il semble que le site de Soğanlı se situe dans la zone délimitée par la diagonale reliant les villes de Nyssa et Podandos (Carte 1). Cette zone appartient au thème de Charsianon et non au thème de Cappadoce.

D'un point de vue religieux, il semble que le site de Soğanlı soit rattaché à l'éparchie de Cappadoce I. Soğanlı s'aligne parfaitement avec les évêchés suffragants d'Hagios Prokopios et Sobesos et s'inscrit dans le cercle que forment les évêchés de Podendos, Dasmendos, Hagios Prokopios (Carte 2). Le site est donc administrativement rattaché au thème de Charsianon dans l'éparchie religieuse de Cappadoce I.

74) Notitia X 29, 465.

75) Hild et Restle 1981 : 231. Les deux auteurs se basent sur la mention dans la vie de Saint Hiéron dont la micro-toponymie ne permet pas de situer précisément les lieux de l'action qui se déroule entre Ancyre, Césarée, Tyane et Mélitène : Métivier $2006: 264$.

76) Un changement important dans l'administration religieuse a lieu au $12^{\mathrm{e}}$ siècle seulement : Moulet $2011: 50$. Les réformes auront lieu plus à l’Est avec la création du thème de Lykandos : Hild et Restle 1981 : 84-105. 


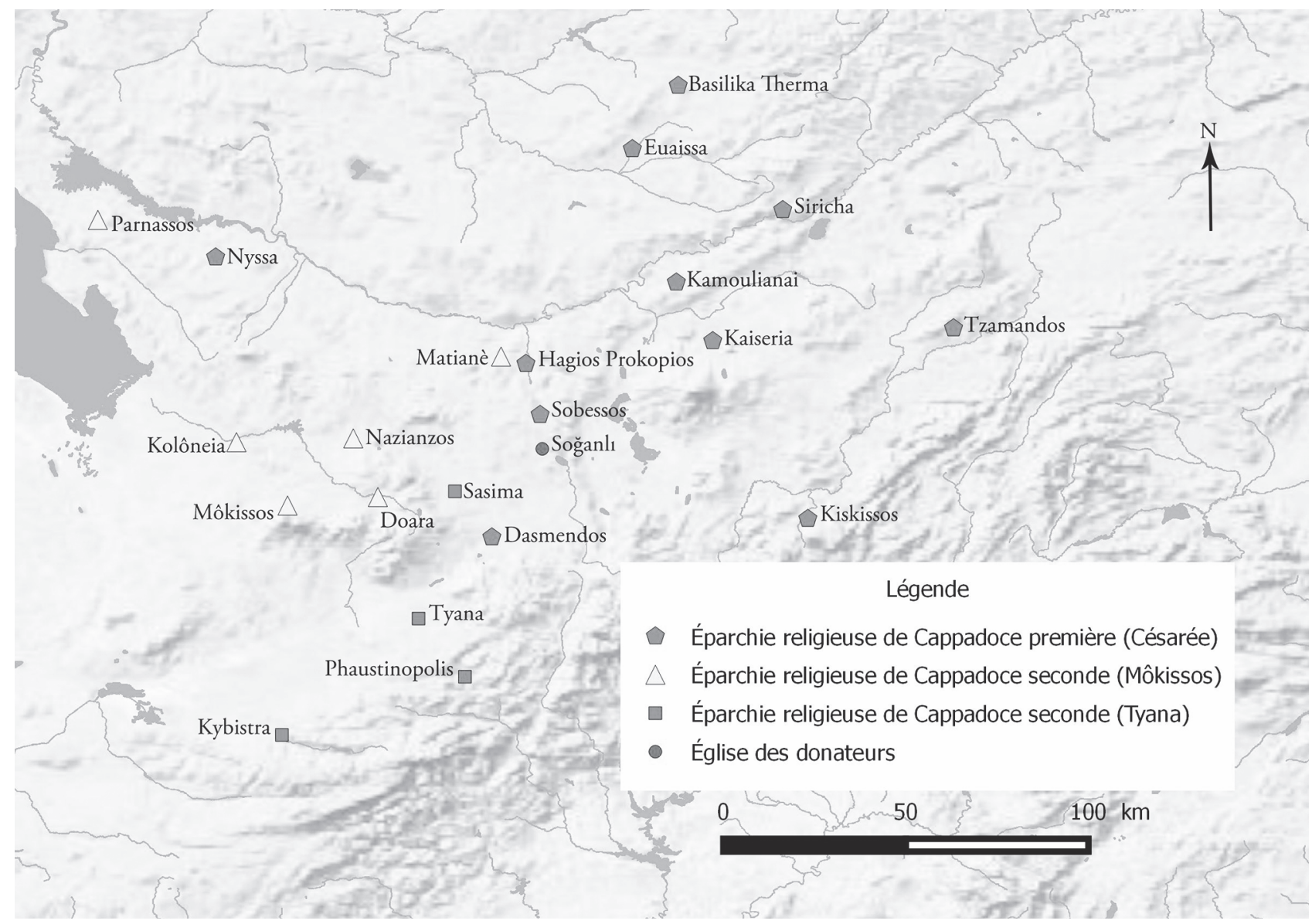

Carte 2 : Carte de la distribution des métropoles et évêchés suffragants des éparchies de Cappadoce.

\section{CONCLUSION}

L'intérêt de replacer l'église et le site dans leurs contextes politique et géographique met en lumière le parallèle entre les églises du thème de Cappadoce et celui de Charsianon tant d'un point de vue artistique qu'historique mais incite à s'interroger sur la pertinence du terme géographique de Cappadoce pour désigner la zone rupestre.

C. Jolivet-Lévy a montré par l'étude d'un panel d'églises rupestres situées dans les deux thèmes, que les choix iconographiques des absides évoluent selon les dates de réalisation des campagnes de décoration et non selon leur localisation ${ }^{77}$. Ces églises rupestres se distinguent parfois de l'ensemble des monuments byzantins par leurs décors absidaux, sans que la localisation de ces sites ait de l'importance $^{78}$. De même, malgré des différences locales dans la réalisation du creusement - on pense notam- ment aux églises à coupole du site de Soğanlı dites Kubbeli qui n'ont pas d'équivalent dans la zone rupestre - les types architecturaux sont identiques dans les églises réalisées dans le Charsianon et en Cappadoce. La chapelle des Donateurs ne semble pas rompre avec ce constat : la mise en scène de la donation est certes originale dans le contexte cappadocien, mais les messages que transmet le décor sont cohérents avec l'ensemble des églises du $11^{\mathrm{e}}$ siècle de la zone rupestre.

Le parallèle entre les deux provinces pourrait être expliqué par le caractère rupestre des monuments qui semble déterminer les choix des peintres et des architectes. Une réponse pourrait également être trouvée dans l'histoire de la zone. Cette zone, bien que séparée en deux thèmes au $9^{\mathrm{e}}$ siècle, était considérée comme une seule et même région. Le développement de grandes familles aristocratiques, formant un réseau d'élites locales paraît avoir lieu avant la 
séparation de la zone en deux thèmes ${ }^{79}$. D'ailleurs dans la littérature mettant en valeur ces familles, il semble que le Charsianon soit considéré comme une partie de la Cappadoce ${ }^{80}$. Cette réflexion sur le Charsianon : "c'était une partie de la Cappadoce, comme tout le monde le sait à l'évidence" pourrait être comprise comme une sorte de propagande afin de valoriser la famille. En effet, l'identité cappadocienne apparaît être un outil politico-religieux dès le $4^{\mathrm{e}}$ siècle chez les Pères de l'Eglise ${ }^{81}$. Cette identité semble devenir un topos dès le $5^{\mathrm{e}}$ siècle et permet de mettre en valeur un individu en le reconnaissant comme Cappadocien. La reprise de ce topos dans l'hagiographie d'un aristocrate byzantin montre la fortune de ce thème littéraire et sa pérennisation durant l'époque médio-byzantine. D'autre part, ces familles aristocratiques dont le caractère militaire explique en grande partie leur fortune forment des groupes homogènes dont les domaines sont répartis dans l'ensemble des deux thèmes ${ }^{82}$. Leurs politiques de propagandes familiales ne devaient pas différer d'un point à un autre de la zone rupestre. Ainsi les
Sképidès, famille aristocratique de moyenne importance, paraissent s'inscrire parfaitement par leur statut dans cette élite provinciale surtout constituée de militaires et de religieux.

L'adoption du terme 'Cappadoce' semble s'inscrire dans la tradition littéraire d'une part, puisqu'à l'époque tardo-antique l'identité cappadocienne devient un enjeu politico-religieux puis un topos qui se pérennise jusqu'au $11^{\mathrm{e}}$ siècle et dans la tradition historiographique d'autre part, puisque le terme est employé pour désigner la zone rupestre au début du $20^{\mathrm{e}}$ siècle.

L'étude de géographie historique permet de rompre avec ces traditions et incite à s'interroger sur la dénomination de 'Cappadoce rupestre'. La zone rupestre à l'époque médio-byzantine ne forme pas un territoire homogène d'un point de vue administratif ou religieux mais l'est par contre d'un point de vue culturel et cette dénomination devrait être privilégiée afin de mieux faire ressortir cette particularité.

A. L.

79) Réflexion autour de ces grandes familles par Kaplan 2006 : 100-117

80) Petit $1902: 550$; Kaplan $2006: 108$ note 52.

81) Basile de Césarée ou Grégoire de Nysse refusent de reconnaître comme Cappadocien Eunome, religieux d'un obscur village des confins de la province : BASILE Contre Eunome, I.1 et GREGOIRE Contre Eunome : I.10, 105. Cette hypothèse, proposée dans le cadre d'une étude réalisée dans mon mémoire de doctorat en cours de réalisation sous la direction de G. Traina, n'est pas retenue par les éditeurs de Basile et Grégoire : BASILE Contre Eunome : 146 note 3 et GREGOIRE Contre Eunome : 191 note 5 et : 192 note 1 : Eunome n'apprécie pas cette erreur car les Galates sont perçus comme une population descendant de Barbares.

82) Certaines à l'image des Maléïnoi possédaient des terres dans les Bucellaires également. Kaplan 2006 : 118. 


\section{BIBLIOGRAPHIE}

\section{Sources}

BASILE Contre Eunome : Basile de Césarée, Contre Eunome, B. Sesboüe (éd. et trad.), Paris, 1982.

De Thematibus : Costantino Porfirogenito. De Thematibus, A. Pertusi (éd.), Vatican, 1952.

De Administrando : Constantine Porphyrogenitus. De Administrando Imperio, G. Moravcsik et R. J. H. Jenkins (éd. et trad.), Washington (D.C.) 1967.

GREGOIRE Contre Eunome : Grégoire de Nysse, Contre Eunome I, 1-146, W. Jaeger et R. Winling (éd. et trad.), Paris, 2008.

HIEROCLES Synekdèmos : Le Synekdèmos d'Hiéroclès et l'opuscule géographique de Georges de Chypre, E. Honigmann, Bruxelles, 1939.

Listes : Les listes de préséance byzantines des IXe et $X^{e}$ siècles, N. Oikonomidès (éd. et trad.), Paris, 1972.

NICEPHORE PHOCAS De Velitatione : Le Traité sur la guérilla, De Velitatione, de l'empereur Nicéphore Phocas, 963-969, G. Dagron et H. Mihăescu (éd. et trad.), Paris, 1986.

Notitia : Notitiae Episcopatuum ecclesiae constanopolitanae, J. Darrouzès (éd.), Paris, 1981.

STRABON Géographie : Strabon, Geographika, S. Radt (éd. et trad.), Göttingen, 2002-2005.

\section{Monographies et articles}

J.-C. Cheynet, J.-C. (ss. dir.), 2006 : Le monde byzantin II. L'Empire byzantin (641-1204), Paris.

- 2010 : "La mise en place des thèmes d'après les sceaux : les stratèges", Studies in Byzantine Sigillography $10: 1-14$

Hild, F. et Restle, M., 1981 : Kappadokien: Kappadokia, Charsianon, Sebasteia und Lykandos, Vienne.

Jerphanion, G. de, 1928-1942 : Une nouvelle province de l'art byzantin: Les églises rupestres de Cappadoce, Paris.

Jolivet-Lévy, C., 1991 : Les églises byzantines de Cappadoce : Le programme iconographique de l'abside et de ses abords, Paris.

- 2002 : Etudes cappadociennes, Londres.

- 2012 : "Militaires et donation en Cappadoce (IX ${ }^{\mathrm{e}}$ $\mathrm{XI}^{\mathrm{e}}$ siècle)", in Spieser, J.-M. et Yota, E. (éds.), Donation et donateurs dans le monde byzantin, Paris : 141-161.

Kaplan, M., 1983 : "Les monastères byzantins et le siècle à Byzance : les investissements des laïques au $\mathrm{XI}^{\mathrm{e}}$ siècle", in: L'Eglise et le siècle de l'an mil au début du $X I I^{e}$ siècle, Actes des congrès de la Société des historiens médiévistes de l'enseignement supérieur public. 14 congrès, Poitiers : 71-83.

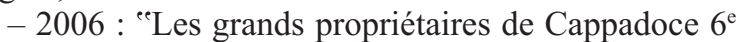
au 11" ${ }^{\mathrm{e}}$, in Byzance villes et campagnes, chapitre 6, Paris : 100-122 ; in Fonseca, C. D. (éd.), Le aree omogenee della civiltà rupestre nell'ambito dell'Impero Bizantin : la Cappadocia, Atti del Quinto Convegno Internazionale di studio sulla civiltà rupestre medioevale nel Mezzogiorno
d'Italia (Lecce-Nardo, 12-16 ottobre 1979), Galatina, $1981: 125-158$

- 2012 : "Les élites rurales byzantines. Historiographie et sources", in: Mélanges de l'école française de Rome 124/2 : 299-312.

Lamesa, A., 2007 : Etude sur la niche dite de prothèse dans les églises du site de Göreme-Kılıçlar en Cappadoce $d u V I^{e}$ au XI ${ }^{e}$ siècle, Mémoire de Master 2 réalisé sous la direction de C. Jolivet-Lévy à l'université de ParisPanthéon Sorbonne, juin 2007 (non publié).

- 2014 : "L'église des donateurs : un inédit sur le site de Soğanlı", Journal de liaison des Amis de la Cappadoce $\mathrm{n}^{\circ} 30: 2-7$.

Lemaigre Demesnil, N., 2002 : "Sculptures figurées d'époque paléochrétienne en Cappadoce : à propos d'un chapiteau historié inédit", Cahiers Archéologiques 50 : 41-50.

- 2010 : Architecture rupestre et décor sculpté en Cappadoce ( $V^{E}-I X^{e}$ siècle), Oxford.

Lemerle, P., 1977 : Cinq études sur le XIe siècle byzantin, Paris.

Mcdonald Kinneir, J., 1818 : Voyage dans l'Asie Mineure, l'Arménie et le Kourdistan dans les années 1813 et1814; suivi des remarques sur les Marches d'Alexandre, et la Retraite des Dix Mille I, N. Perrin (trad.), Paris.

Métivier, S., 2005 : La Cappadoce (IVe-VIe siècle). Une histoire provinciale de l'Empire romain d'Orient, Paris.

- 2006 : "Le culte de Saint Hiéron", in Caseau, B., Cheynet, J-C. et Déroche, V. (éds.), Pèlerinages et lieux saints dans l'Antiquité et le Moyen Âge. Mélanges offerts à Pierre Maraval, Paris : 263-279.

- 2008 : "L'organisation de la frontière arabobyzantine en Cappadoce (VIII ${ }^{\mathrm{e}}$-IX ${ }^{\mathrm{e}}$ siècle) ", in Cuozzo, E., Déroche, V., Peters-Custot, A. et Prigent, V. (éds.), Puer Apuliae. Mélanges offerts à Jean-Marie Martin, Paris : 433-454.

Moulet, B., 2011 : Evêques, pouvoir et société à Byzance, VIII $-X I^{e}$ siècle : territoires, communautés et individus dans la société provinciale byzantine, Paris.

Parani, C., 2003 : Reconstructing the Reality of Images. Byzantine Material Culture and Religious Iconography $\left(11^{\text {th }}-15^{\text {th }}\right.$ Centuries $)$, Leiden.

Pertusi, A., 1958 : "La formation des thèmes byzantins", in Berichte zum XI. Internationalen Byzantinisten-Kongress I, Munich : 1-40.

Petit, L., 1902 : "Vie de Saint Michel Maléinos suivie du traité ascétique de Basile Maléinos", Revue de l'Orient chrétien VII : 543-603.

Rambaud, A., 1870 : L'empire grec au $X^{e}$ siècle : Constantin Porphyrogénète, Paris.

Ramsay, W. M., 1890 : The historical geography of Asia Minor, Londres.

Restle,, M. 1967 : Die byzantinische Wandmalerei in Kleinasien, Recklinghausen.

Rodley, L., 1985 : Caves Monasteries of Byzantine Cappadocia, Cambridge. 
Thierry, N., 1963 : Nouvelles églises rupestres de Cappadoce : Région du Hasan Dagi, Paris.

- 1975 : "L'art monumental byzantin en Asie Mineure du XIe au XIV"e, Dumbarton Oaks Papers 29 : 73-111.

- 1995 : "De la datation des églises de Cappadoce", Byzantinische Zeitschrift 88/2 : 419-455.

- 2002 : N. Thierry, La Cappadoce de l'Antiquité au Moyen Age, Turnhout.

Walter, C., 1982 : Art and Ritual of the Byzantine Church, Londres.
Zgusta, L., 1984 : Kleinasiatische Ortsnamen, Heidelberg.

\section{Source en ligne}

Berger, A., : s.v. "Tohannes", in Cancik, H. et Schneider, H. (éds.), Brill's New Pauly Antiquity volumes, Brill Online.

http://referenceworks.brillonline.com.janus.biu.

sorbonne.fr/entries/brill-s-new-pauly/iohannes-e525780 


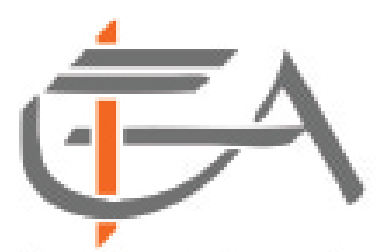

Institut Français d'Etudes Anatoliennes

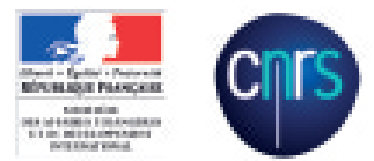

Eglise paléochrétienne de Bindéos (Pisidie), détail de la mosaïque ornant le sal de la nef centrale, $4^{e} \mathrm{~s}$. ap. J.-C. 